\title{
Differential Interactions of Heparin and Heparan Sulfate Glycosaminoglycans with the Selectins \\ Implications for the Use of Unfractionated and Low Molecular Weight Heparins as Therapeutic Agents
}

\author{
Andrea Koenig, Karin Norgard-Sumnicht, Robert Linhardt, ${ }^{*}$ and Ajit Varki \\ Glycobiology Program, UCSD Cancer Center, Divisions of Hematology-Oncology, and Cellular and Molecular Medicine, University of \\ California, San Diego, La Jolla, California 92093; and *Division of Medicinal and Natural Products Chemistry, Department of Chemical \\ and Biochemical Engineering, University of Iowa College of Pharmacy, Iowa City, Iowa 52242
}

\begin{abstract}
The selectins are calcium-dependent C-type lectins that bind certain sialylated, fucosylated, sulfated glycoprotein ligands. L-selectin also recognizes endothelial proteoglycans in a calcium-dependent manner, via heparan sulfate (HS) glycosaminoglycan chains enriched in unsubstituted glucosamine units. We now show that these HS chains can also bind P-selectin, but not E-selectin. However, while L-selectin binding requires micromolar levels of free calcium, P-selectin recognition is largely divalent cation-independent. Despite this, HS chains bound to P-selectin are eluted by ethylenediamine tetraacetic acid (EDTA), but only at high concentrations. Porcine intestinal mucosal (mast cell-derived) heparin (PIM-heparin) shows similar properties, with no binding to E-selectin, calcium-dependent binding of a subfraction to L-selectin and to P-selectin, and calcium-independent binding of a larger fraction to P-selectin, the latter being disrupted by high EDTA concentrations. Analysis of defined heparin fragment pools shows a size dependence for interaction, with tetradecasaccharides showing easily detectable binding to L- and P-selectin affinity columns. L-selectin binding fragments include more heavily sulfated and epimerized regions and, as with the endothelial HS chains, they are enriched in free amino groups. The P-selectin binding component includes this fraction as well as some less highly modified regions. Thus, endothelium-derived HS chains and mast cell-derived heparins could play a role in modulating the biology of selectins in vivo.

Notably, P- and L-selectin binding to sialyl-Lewis ${ }^{\mathrm{x}}$ and to HL-60 cells (which are known to carry the native ligand PSGL-1) is inhibited by unfractionated pharmaceutical heparin preparations at concentrations 12-50-fold lower than those recommended for effective anticoagulation in vivo. In contrast, two low molecular weight heparins currently considered as clinical replacements for unfractionated heparin are much poorer inhibitors. Thus, patients undergoing hep-
\end{abstract}

Address correspondence to Ajit Varki, Cancer Center, 0687, UCSD School of Medicine, La Jolla, CA 92093-0687. Phone: 619-534-3296; FAX: 619-534-5611; E-mail: avarki@ucsd.edu

Received for publication 15 August 1997 and accepted in revised form 29 December 1997.

J. Clin. Invest.

(C) The American Society for Clinical Investigation, Inc. 0021-9738/98/02/0877/13 \$2.00

Volume 101, Number 4, February 1998, 877-889

http://www.jci.org arin therapy for other reasons may be experiencing clinically significant inhibition of L- and P-selectin function, and the current switchover to low-molecular weight heparins may come at some loss of this effect. Low-dose unfractionated heparin should be investigated as a treatment option for acute and chronic diseases in which P- and L-selectin play pathological roles. (J. Clin. Invest. 1998. 101:877-889.) Key words: endothelium $\bullet$ proteoglycans $\bullet$ sulfate $\bullet$ affinity chromatography $\bullet$ selectin inhibition

\section{Introduction}

The selectins, L-, E-, and P-selectin, are a family of glycoproteins mediating the initial adhesive events directing the homing of lymphocytes into lymphoid organs, as well as the interactions of leukocytes with endothelium in inflammation and reperfusion injury states (1-20). Some evidence suggests that selectin interactions may also be primary adhesive mechanisms involved in the metastasis of certain epithelial cancers (21-26). To date, almost all high-affinity interactions mediated by the selectins seem to involve the calcium-dependent recognition of specific carbohydrate structures on the opposing cells. Because selectin interactions are implicated in many disease states, much work has been done to find small carbohydrate molecules for use as competitive inhibitors to block these interactions. One oligosaccharide structure, sialyl-Lewis ${ }^{x}$ [SLe ${ }^{\mathrm{x}}{ }^{1}$ Sia 2 2-3Gal $\beta 1-4$ (Fuc $\alpha 1-3$ )GlcNAc], is being studied extensively for this purpose. This tetrasaccharide can be recognized by all three selectins (3-8, 11, 13-15, 19, 27-34), and genetic data indicate that this and related structures are required for selectin function in vivo $(35,36)$. Indeed, SLe ${ }^{\mathrm{x}}$ is a critical component of many naturally occurring high-affinity selectin ligands, e.g., the myeloid cell ligand for P-selectin, called PSGL-1 (20, 37, 38). However, the interaction of selectins with pure $\mathrm{SLe}^{\mathrm{x}}$ is weak, and high-affinity recognition of sialylated fucosylated ligands by the selectins seems to involve higher order carbohydrate structures, perhaps generated by clustering of sugar chains $(5,11,19,37)$. Thus, while $\mathrm{SLe}^{\mathrm{x}}$ and related structures appear promising for therapeutic use $(2,18,39-44)$, they have some drawbacks, being weak inhibitors, and being very expensive to produce in the quantities required for treat-

1. Abbreviations used in this paper: CPAE, calf pulmonary artery endothelial (cells); HONO, nitrous acid; HS, heparan sulfate; HUVEC, human umbilical vein endothelial cells; LMW heparin, low molecular weight heparin; PAS, protein A-Sepharose; PIM-heparin, porcine intestinal mucosal heparin; PSGL-1, P-selectin glycoprotein ligand 1; $\mathrm{Rg}$, receptor globulin; RT, room temperature; $\mathrm{SLe}^{\mathrm{x}}$, sialyl Lewis $;$ Vo, void volume. 
ment. Furthermore, they demonstrate relatively little selectivity among the selectins. On the other hand, artificial macromolecular ligands may have their own pharmacological limitations $(45,46)$. Thus, a search for different classes of glycoconjugates that bind to the selectins is worthwhile.

Prior work has shown that L-selectin and P-selectin binding are similar to each other (and different from E-selectin) in their ability to be inhibited and/or bound by several compounds containing sulfate groups (47-56). Included among the compounds originally studied were porcine intestinal mucosal heparin (PIM-heparin) and its fragments. However, because so many natural and artificial sulfated compounds seemed to have similar effects, the biological and clinical relevance of heparin-binding by selectins was not pursued extensively. Subsequently, we reported heparin-like molecules from calf pulmonary artery endothelial (CPAE) cells which bind to L-selectin in a calcium-dependent manner (57). In a follow-up study (58), we further characterized the CPAE-derived ligand as heparan sulfate (HS) proteoglycan(s), the released HS glycosaminoglycan chains of which are able to bind specifically to L-selectin. Surprisingly, these L-selectin binding chains were found to have a significant amount of novel glucosamine residues, which are not substituted with either an acetyl group or a sulfate group. Very recently, others have shown a sulfate- but not sialic acid-dependent binding of L-selectin to coronary microvascular endothelium (59), and Giuffre and co-workers have demonstrated directly that HS chains expressed on cultured bovine aortic endothelial cells can act as functional ligands for L-selectin (60).

In this work, we ask if these endothelial HS chains are able to interact with the other two known members of this adhesion receptor family (E- and P-selectin), and investigate the calcium dependence of these interactions. We have also studied the interactions of all three selectins with PIM-heparin and with size-defined fragments derived from this polymer. Finally, we have asked if inhibition of selectin binding can occur at concentrations of heparin that are in the typical range for its use as a therapeutic anticoagulant $(61,62)$. We find that this is indeed the case, and note a striking difference between the activity of the traditional pharmaceutical preparations of unfractionated heparin, and that of some of the currently popular low molecular weight (LMW) heparins (61-71).

\section{Methods}

Materials. Most of the materials used were obtained from the Sigma Chemical Co. (St. Louis, MO). The following materials were obtained from the sources indicated: Arthrobacter ureafaciens neuraminidase (sialidase), Calbiochem Corp. (La Jolla, CA); proteinase K, GIBCO BRL (Gaithersburg, MD); $\left[{ }^{3} \mathrm{H}\right] \mathrm{GlcNH}_{2}(60 \mathrm{Ci} / \mathrm{mmol})$, American Radiolabeled Chemicals (St. Louis, MO); $\mathrm{NaB}\left[{ }^{3} \mathrm{H}\right]_{4}(11.8 \mathrm{Ci} / \mathrm{mmol})$, New England Nuclear (Boston, MA); trypsin-TPCK, Worthington Biochemical Corp. (Freehold, NJ); DFP, Aldrich Chemical Co. (Milwaukee, WI); and Centricon-3 concentrators, Amicon, Inc. (Beverly, MA). All other chemicals were of reagent grade or better, and were from commercial sources. Heparin lyases (I, II, and III) were either purified to homogeneity (72), or purchased from Sigma Chemical Co. Size-fragmented mixtures of PIM-heparin were prepared as described previously (73). The recombinant L-selectin Ig-fusion chimeric protein was prepared as described (74), and the E- and P-selectin Ig-fusion chimeric constructs were produced using vectors originally prepared by Aruffo and colleagues $(22,75)$. Unfractionated heparin formulated for clinical use $(10,000$ or $1,000 \mathrm{U} / \mathrm{ml})$ was ob- tained from Elkins-Sinn Inc. (Cherry Hill, NJ). The LMW heparins Lovenox and Fragmin were gifts from Dr. Dzung Le (UCSD Department of Pathology).

Cell lines. CPAE cells were from American Type Culture Collection (Rockville, MD) (CCL 209) and were used at or before passage 23. Human umbilical vein endothelial cells (HUVECs) were from Clonetics (San Diego, CA) (CC-2008), and were used within the first three passages. Cells were grown to subconfluence (80\%), and labeling with $\left[{ }^{3} \mathrm{H}\right] \mathrm{GlcNH}_{2}$ was done as reported earlier $(57,76)$. HL-60 cells, a human promyelocytic leukemia cell line, were obtained from American Type Culture Collection (CCL 240) and used at or before passage 8 . These cells were grown in RPMI 1640 media supplemented with $20 \%$ FBS, $1 \%$ Pen-Strep, and $0.2 \%$ gentamycin, and labeled with $\left[{ }^{3} \mathrm{H}\right]$ thymidine as described below.

Preparation of free HS chains from endothelial cells. Free HS chains were released from $\left[{ }^{3} \mathrm{H}\right] \mathrm{GlcNH}_{2}$-labeled HUVEC or CPAE cell proteoglycans and purified as described previously (58). The free HS chains (which are able to interact with L-selectin) were then isolated by application to an L-selectin affinity column as described below.

Preparation of $\left[{ }^{3}\right.$ H]heparin samples. $20-120 \mathrm{nmol}$ of di- to tetradecasaccharide heparin samples was brought up to a volume of 100 $\mu l$ with $0.2 \mathrm{M}$ sodium borate buffer, $\mathrm{pH} 10$. A $5 \times$ molar excess of $\mathrm{NaB}\left[{ }^{3} \mathrm{H}\right]_{4}, \sim 1.4-7 \mathrm{mCi}$ of $\mathrm{NaB}\left[{ }^{3} \mathrm{H}\right]_{4}$ (depending on the amount of nanomoles per sample), was added to each sample and allowed to react at room temperature (RT). After $4 \mathrm{~h}, 40 \mu \mathrm{l}$ of $1 \mathrm{M} \mathrm{NaBH}_{4}$ was added to the samples, and $1 \mathrm{~h}$ later, $40 \mu \mathrm{l}$ of acetone was added to quench the reaction. The next day, $150 \mu \mathrm{l}$ of $1.0 \mathrm{M}$ ammonium formate $\mathrm{pH} 5$ was added to the samples to lower the $\mathrm{pH}$ and dissociate borate complexes. Samples were stored at $-80^{\circ} \mathrm{C}$ until desalting was done on 6 ml Bio-Gel P-2 (150-4114; Bio-Rad Laboratories, Richmond, CA), packed into $10-\mathrm{ml}$ plastic pipet columns in $100 \mathrm{mM}$ ammonium formate buffer, $\mathrm{pH}$ 5. The void volume (Vo) and included volume (Vi) were determined by loading $400 \mu \mathrm{l} 0.1 \%$ blue dextran (detected by color) in $100 \mathrm{mM}$ ammonium formate buffer, $\mathrm{pH}$ 5, plus $200 \mathrm{mM} \mathrm{NaCl}$ (detected with $\mathrm{AgNO}_{3}$ ). The columns were eluted in $100 \mathrm{mM}$ ammonium formate buffer, $\mathrm{pH} 5$, and 500- $\mu$ l fractions were collected. Samples were loaded onto separate Bio-Gel P-2 columns, and monitored by $\left[{ }^{3} \mathrm{H}\right] \mathrm{cpm}$ counting $1 \%$ of each collection vial. Fractions containing the $\mathrm{Vo}_{0}\left[{ }^{3} \mathrm{H}\right] \mathrm{cpm}$ were pooled, lyophilized, dissolved in a small amount of $\mathrm{H}_{2} \mathrm{O}$, and stored at $-20^{\circ} \mathrm{C}$ until further use. This method does not completely clean up the di- and tetrasaccharides, so Sephadex G-15 chromatography was used in addition (see below).

Selectin affinity chromatography of endothelial HS chains. Affinity columns of the three selectin receptor globulins (Rgs) were prepared by immobilizing $0.5 \mathrm{mg}$ of each on $0.5 \mathrm{ml}$ of protein A-Sepharose (PAS). The endothelial HS chains were bound to the selectin columns in $100 \mathrm{mM} \mathrm{NaCl}, 20 \mathrm{mM}$ Mops (pH 7.4), $1 \mathrm{mM} \mathrm{CaCl}_{2}, 1 \mathrm{mM}$ $\mathrm{MgCl}_{2}$, and specifically eluted using the above binding buffer in which the $\mathrm{CaCl}_{2}$ and $\mathrm{MgCl}_{2}$ were replaced with $5 \mathrm{mM}$ EDTA. For P-selectin only, the ligands were also eluted by increasing the EDTA concentration to $20 \mathrm{mM}$ (see Results for rationale). For the PIM-heparin studies, we chose to work in more precisely physiological salt concentrations (77). The binding buffer was $20 \mathrm{mM}$ Hepes, $125 \mathrm{mM} \mathrm{NaCl}, 2 \mathrm{mM}$ $\mathrm{CaCl}_{2}, 2 \mathrm{mM} \mathrm{MgCl}$ (pH 7.45). The first elution was carried out with the same buffer containing $2 \mathrm{mM}$ EDTA in place of $2 \mathrm{mM} \mathrm{CaCl}_{2}$ and $2 \mathrm{mM} \mathrm{MgCl}_{2}$; the second elution was with $20 \mathrm{mM}$ Hepes ( $\mathrm{pH} 7.45$ ), $110 \mathrm{mM} \mathrm{NaCl}, 20 \mathrm{mM}$ EDTA. Also, we made denser selectin affinity columns, containing $1.7 \mathrm{mg}$ selectin-Rg to $1 \mathrm{ml}$ PAS. In experiments exploring calcium dependency, the $2 \mathrm{mM} \mathrm{CaCl}_{2}$ and $2 \mathrm{mM} \mathrm{MgCl}_{2}$ in either of the above buffers was replaced with $3 \mathrm{mM} \mathrm{MgCl}_{2}$ with $5 \mathrm{mM}$ EGTA; the $\mathrm{NaCl}$ concentration was adjusted so that the final osmolarity was 300 mosM, and the $\mathrm{pH}$ remained constant. Thus, the three buffers used in eluting material from the columns that correspond to the three described above consist of: (a) $20 \mathrm{mM}$ Hepes (pH 7.45), $3 \mathrm{mM}$ $\mathrm{MgCl}_{2}, 5 \mathrm{mM}$ EGTA, $122 \mathrm{mM} \mathrm{NaCl}$; (b) $20 \mathrm{mM}$ Hepes (pH 7.45), $3 \mathrm{mM} \mathrm{MgCl}_{2}, 5 \mathrm{mM}$ EGTA, $117 \mathrm{mM} \mathrm{NaCl}, 5 \mathrm{mM}$ EDTA; and (c) 20 mM Hepes (pH 7.45), 3 mM MgCl, 5 mM EGTA, $102 \mathrm{mM} \mathrm{NaCl}, 20$ mM EDTA. 
Isolation of $\left[{ }^{3} \mathrm{H}\right]$ tetradecasaccharides that bound or did not bind to $L$ - and P-selectin. The $\left[{ }^{3} \mathrm{H}\right]$ tetradecasaccharides that bound to $\mathrm{L}$ and P-selectin to this sample were isolated on affinity columns. Approximately $500,000 \mathrm{cpm}$ of $\left[{ }^{3} \mathrm{H}\right]$ tetradecasaccharide was loaded over both L- and P-selectin affinity columns, and fractions were collected as described above, except that only $0.5 \%$ of each fraction was monitored for radioactivity. Centricon-3 (cat. No. 4203; Amicon, Inc.) concentrator units were used to concentrate and desalt the run-through and eluted fractions. Overall recoveries ranged from 50 to $99 \%$. The isolated pools of $\left[{ }^{3} \mathrm{H}\right]$ tetradecasaccharides were stored in $\sim 250 \mu \mathrm{l}$ water at $4^{\circ} \mathrm{C}$ for use during the following experiments.

Rebinding and cross-binding experiments. To determine whether the $\left[{ }^{3} \mathrm{H}\right]$ tetradecasaccharides rebound to the selectin affinity columns, $\sim 2,500 \mathrm{cpm}$ of each pool was run over the same selectin affinity column as in the first run, samples were collected, and $\left[{ }^{3} \mathrm{H}\right]$ radioactivity was monitored as before. For the cross-binding experiments, the same chromatography experiment was done as in the rebinding experiments, except that the sample was placed over the second column. E-selectin was not used in these experiments since none of the PIM-heparin samples originally bound to E-selectin.

Nitrous acid (HONO) degradation. HONO degradation was performed by the method of Conrad et al. (78). $100 \mu \mathrm{l}$ of either the $\mathrm{pH}$ 1.5 or $\mathrm{pH} 4.0 \mathrm{HONO}$ reagent was added to tubes containing $\sim 2,000$ cpm of the $\left[{ }^{3} \mathrm{H}\right]$ tetradecasaccharide and each pooled fraction isolated from the L- and P-selectin affinity columns. The reaction occurred for $10 \mathrm{~min}$ at RT and was quenched with $15 \mu \mathrm{l}$ of $1 \mathrm{M} \mathrm{Na}_{2} \mathrm{CO}_{3}$ for the $\mathrm{pH}$ 4.0 reaction; and with $35 \mu \mathrm{l}$ of $1 \mathrm{M} \mathrm{Na}_{2} \mathrm{CO}_{3}$ for the $\mathrm{pH} 1.5$ reaction. The final $\mathrm{pH}$ for all samples was $\sim 7.5$. Controls for the $\mathrm{pH}$ of each reaction were used for every experiment, and consisted of replacing the sodium nitrite with sodium acetate for the $\mathrm{pH} 4.0$ reaction, and barium nitrite with barium acetate for the $\mathrm{pH} 1.5$ reaction. Samples were stored at $-20^{\circ} \mathrm{C}$ until FPLC analysis.

Heparin lyase treatments. Approximately 2,000 cpm of the $\left[{ }^{3} \mathrm{H}\right]$ tetradecasaccharide and each pooled fraction isolated from the Land P-selectin affinity columns was treated with either of the three heparin lyases as described $(72,79-81)$, using $0.1-0.05 \mathrm{U}$ of enzyme to digest the $\left[{ }^{3} \mathrm{H}\right]$ tetradecasaccharide, and $0.05 \mathrm{U}$ used to digest each of the pools. Enzyme digestion occurred at $30^{\circ} \mathrm{C}$ for $8.5 \mathrm{~h}$ in sodium phosphate/ $\mathrm{NaCl}$ buffer, $\mathrm{pH}$ 7.1. $0.1 \mathrm{U}$ of heparin lyase II was used to digest all samples for $8 \mathrm{~h}$ at $35^{\circ} \mathrm{C}$ in sodium phosphate, buffer, $\mathrm{pH}$ 7.1. $0.2 \mathrm{U}$ of heparin lyase III was used to digest all samples for $11 \mathrm{~h}$ at $35^{\circ} \mathrm{C}$ in sodium phosphate buffer, $\mathrm{pH}$ 7.6. All reactions were stopped by boiling for $5 \mathrm{~min}$; samples were stored at $-20^{\circ} \mathrm{C}$ until FPLC analysis. Under these conditions, all digestions went to completion.

Superose-12 FPLC fractionation. A Superose 12 HR 10/30 column (Pharmacia Biotech, Piscataway, NJ) was used exactly as described earlier (58), both to analyze the size of the samples and to remove unreacted small products and reagents. The elution profile of this column was highly reproducible from run to run, as determined by the markers blue dextran (Vo), ${ }^{35}$ S $]$ sodium sulfate (total volume), and ${ }^{3} \mathrm{H}$-labeled heparin fragments (partially included).

Superdex 75 FPLC fractionation. A Superdex 75 HR 10/30 column (Pharmacia Biotech) was used to analyze the size of the products from the enzymatic (heparin lyases I, II, and III) and chemical treatments (HONO pH 1.5 and 4.0 ) of the $\left[{ }^{3} \mathrm{H}\right]$ tetradecasaccharide starting mixture, and the L- and $\mathrm{P}$-selectin binding and nonbinding $\left[{ }^{3} \mathrm{H}\right]$ tetradecasaccharide pools. The column was run isocratically in the same buffer used for the selectin-Rg-PAS columns: $20 \mathrm{mM}$ Hepes (pH 7.45), $125 \mathrm{mM} \mathrm{NaCl}, 2 \mathrm{mM} \mathrm{MgCl}, 2 \mathrm{mM} \mathrm{CaCl}_{2}$. A FPLC system (P-LKB-Pump P-500 and P-LKB-Controller LCC-500 Plus; Pharmacia Biotech) was used to elute the column at $1.0 \mathrm{ml} / \mathrm{min}$ flow rate with an on-line LKB-Frac 100 fraction collector programmed to collect 0.25 -min fractions after $6 \mathrm{~min}$ from the beginning of the run, to 21 $\min$. The total number of fractions per run is 60 . Fractions were collected in scintillation vials, $3 \mathrm{ml}$ of Liquiscint scintillation fluid was added, and the radioactivity was determined. The elution profile of this column was highly reproducible from run to run, as determined by addition of markers: blue dextran (Vo) and PIM-heparin sized mixtures ranging from di- to tetradecasaccharides, which were radiolabeled on the reducing terminus with $\mathrm{NaB}\left[{ }^{3} \mathrm{H}\right]_{4}$ as described above. $50 \mu \mathrm{l}$ of $1 \%$ blue dextran was added to every sample before loading onto the Superdex 75 FPLC column to confirm reproducibility from run to run.

ELISA inhibition assays. ELISA inhibition assays were done by the method previously reported $(45,77)$. Sterile polystyrene 96 -well ELISA plates (No. 25801; Corning, Corning, NY) were coated with $200 \mathrm{ng}$ of polyacrylamide-SLe ${ }^{\mathrm{x}}$ (No. 18205PA; Glycotech, Rockville, MD) by overnight incubation at $4^{\circ} \mathrm{C}$ in $100 \mu$ l of $50 \mathrm{mM}$ sodium carbonate/bicarbonate buffer, $\mathrm{pH}$ 9.5. Plates were then blocked with 200 $\mu \mathrm{l} /$ well of assay buffer: $20 \mathrm{mM}$ Hepes (No. 16926; United States Biochemical Corp., Cleveland, OH), $125 \mathrm{mM} \mathrm{NaCl}, 2 \mathrm{mM} \mathrm{CaCl}_{2}, 2 \mathrm{mM}$ $\mathrm{MgCl}_{2}, 1 \%$ protease-free BSA (No. 82-045-1; Pentex, Miles Inc., Kankakee, IL), pH 7.45 (osmolality 290 mosmol, determined with a Vapor Pressure Osmometer, model 5500XR; Wescor Inc., Logan, UT) for a minimum of $2 \mathrm{~h}$ at $4^{\circ} \mathrm{C}$. During the blocking step, the selectin chimeras were preincubated separately at $4^{\circ} \mathrm{C}$ with the secondary antibody, peroxidase-conjugated goat anti-human IgG (No. 109-035098; Jackson ImmunoResearch Laboratories, Inc., West Grove, PA) in assay buffer for $\sim 1 \mathrm{~h}$. Final selectin-Rg concentration was $20 \mathrm{nM}$, and the optimal secondary antibody dilution was determined to be 1:1,000 for the particular serum used. Potential inhibitors were serially diluted in assay buffer at twice the final required concentration. The selectin- $\mathrm{Rg} / \mathrm{secondary}$ antibody stock was aliquoted into tubes containing an equivalent volume of inhibitor solution; buffer alone for the positive control, or buffer with $10 \mathrm{mM} \mathrm{Na}_{2}$ EDTA, $\mathrm{pH} 7.5$, for the negative control (final concentration $5 \mathrm{mM}$ EDTA). These tubes were preincubated at $4^{\circ} \mathrm{C}$ for $30 \mathrm{~min}$, and added to ELISA plates, in duplicates, at final well volume of $100 \mu \mathrm{l}$. After $4 \mathrm{~h}$ of plate incubation at $4^{\circ} \mathrm{C}$, plates were washed three times with $200 \mu \mathrm{l} /$ well of assay buffer at $4^{\circ} \mathrm{C}$, followed by development with $150 \mu \mathrm{l} /$ well of $o$-phenylenediamine dihydrochloride (OPD) solution at RT: $0.002 \mathrm{mg}$ $\mathrm{OPD} / \mathrm{ml}$ in $50 \mathrm{mM}$ sodium citrate, $50 \mathrm{mM}$ disodium phosphate buffer, $\mathrm{pH} 5.2$ containing $1 \mu \mathrm{l} / \mathrm{ml} 30 \% \mathrm{H}_{2} \mathrm{O}_{2}$. Using a timer, each well was sequentially quenched with $40 \mu \mathrm{l}$ of $4 \mathrm{M} \mathrm{H}_{2} \mathrm{SO}_{4}$ after a fixed time of peroxidase reaction. Softmax software and a microplate reader (Molecular Devices, Inc., Menlo Park, CA) determined and recorded absorbance at $492 \mathrm{nM}$. Before curve fitting, the data were changed into percentages for comparative purposes, using the formula: [(average of duplicates) - (negative control) $] /[$ (positive control) $-($ negative control $)] \times 100$, again with the Softmax software.

$H L-60$ cell-selectin binding inhibition assays. HL-60 cells were labeled with $\left[{ }^{3} \mathrm{H}\right]$ thymidine at a concentration of $1 \mu \mathrm{Ci} / \mathrm{ml}$ media, beginning $2 \mathrm{~d}$ before inhibition experiments. The labeled cells used for inhibition experiments were at or below $\sim 2 \times 10^{6}$ cells $/ \mathrm{ml}$. The cells were collected by low speed centrifugation, washed three times with $20 \mathrm{ml}$ of media, resuspended, and the cell count and radioactivity were determined. Radioactivity ranged from 0.3 to $1.7 \mathrm{cpm} / \mathrm{cell}$, and the cells added ranged from $10^{4}$ to $10^{5}$ cells/well. L- and P-selectinRgs (1 pmol/well) were immobilized onto 24-well tissue culture plates (Costar Corp., Cambridge, MA) in $250 \mu \mathrm{l}$ of $50 \mathrm{mM}$ sodium carbonate/bicarbonate buffer, $\mathrm{pH} 9.5$, for $8-12 \mathrm{~h}$ at $4^{\circ} \mathrm{C}$. The plates were blocked for $2 \mathrm{~h}$ at $4^{\circ} \mathrm{C}$ with $500 \mu \mathrm{l} /$ well with $20 \mathrm{mM}$ Hepes, $125 \mathrm{mM}$

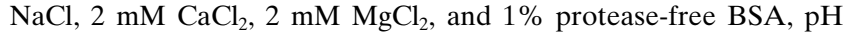
7.45. Serial dilutions of unfractionated and LMW heparins were prepared in duplicate as described above for the ELISA experiments and aliquots of $\left[{ }^{3} \mathrm{H}\right] \mathrm{HL}-60$ cells added for a final volume of $250 \mu \mathrm{l}$ applied to each well. Positive control wells with $\left[{ }^{3} \mathrm{H}\right] \mathrm{HL}-60$ cells alone and negative controls including $20 \mathrm{mM}$ EDTA were analyzed in triplicate. After incubation for $3-4 \mathrm{~h}$ at $4^{\circ} \mathrm{C}$ with gentle rotation on an Orbital Rotor at $70 \mathrm{rpm}$, the wells were washed three times with cold assay buffer minus the BSA at a volume of $500 \mu \mathrm{l} /$ well. Bound cells were solubilized at RT for $10 \mathrm{~min}$ in $1 \%$ Triton X-100 (United States Biochemical Corp.), and the lysate was monitored for radioactivity. $\mathrm{IC}_{50}$ values were expressed as a percentage of the positive control and calculated exactly as described above for the ELISA inhibition experiments. 


\section{Results}

Endothelial HS ligands for L-selectin also bind to P-selectin but not to E-selectin. In a previous study (58), we showed that a subset of metabolically labeled HS chains released from endothelial cell HS proteoglycans was able to bind to L-selectin. To determine if there was any cross-recognition of these HS ligands by the other selectins, we used selectin-chimera affinity columns in which each of the three selectin molecules were immobilized on PAS beads at similar densities. ${ }^{2}$ Similar amounts of $\left[{ }^{3} \mathrm{H}\right] \mathrm{GlcNH}_{2}$-metabolically labeled L-selectin binding HS chains from CPAE cells were applied to each column. As shown in Fig. 1, most of this ligand rebound to the L-selectin column and eluted with $5 \mathrm{mM}$ EDTA. In contrast, none bound to the E-selectin column (the E-selectin column is known to be functional because it is capable of binding other ligands from carcinoma cells in a calcium-dependent manner) (Kim, Y., and A. Varki, unpublished results). While all of the ligand also bound to the P-selectin column, it was eluted very poorly with $5 \mathrm{mM}$ EDTA (see Fig. 1, bottom, inset). Similar results were seen with $\left[{ }^{35} \mathrm{~S}\right]$ sulfate-labeled material, and with labeled HS chains from HUVEC cells (data not shown). Thus, a P-selectin column of similar density completely bound the L-selectin HS ligands from both the CPAE and the HUVEC cells, but showed a very slow and partial elution with 5 mM EDTA. This slow release stopped when the column was adjusted back into the calcium-containing loading buffer (data not shown), indicating that elution was specific for the inclusion of EDTA. Subsequent elution with a higher concentration of EDTA (20 $\mathrm{mM}$ ) resulted in recovery of all of the labeled ligand from both cell sources (data not shown). This difference suggests that the eluting effect of EDTA with P-selectin might not be strictly based upon its calcium-chelating properties (see below). Therefore, most further elutions of the P-selectin column were done first with $2 \mathrm{mM}$ EDTA, and then with $20 \mathrm{mM}$ EDTA, which allowed for recovery of all labeled ligands.

Comparison of calcium dependence of HS chain binding to $L$ - and P-selectin. Most previously reported high-affinity interactions of the selectins have been dependent on calcium. This fits well with the fact that the amino-terminal region of the selectin molecules resembles C-type (or calcium-dependent) lectin-binding domains, and with direct observations of calcium ion interactions with the selectins $(82,83)$. In addition to calcium, another divalent cation, magnesium, has been used in all buffers used for selectin affinity chromatography, because it was reported that magnesium potentiated the effects of the calcium in P-selectin binding (84). However, since the HS ligands studied here are so different from the previously described sialylated ligands $(3-8,11,13-15,19,27-34,85)$, it was important to confirm whether the interactions we observed were calcium dependent. Simply leaving out calcium from the binding buffer did not change the results (data not shown). However, there is a trace contamination of calcium $(\sim 50 \mu \mathrm{M})$ present in a $2 \mathrm{mM}$ magnesium-containing buffer, which could be sufficient to support L-selectin binding. In-

2. The binding activity of columns for HS chains seems to be somewhat density dependent, and one column may not bind all of the ligand which another one can. However, the amount capable of binding to a given column is very consistent from experiment to experiment.

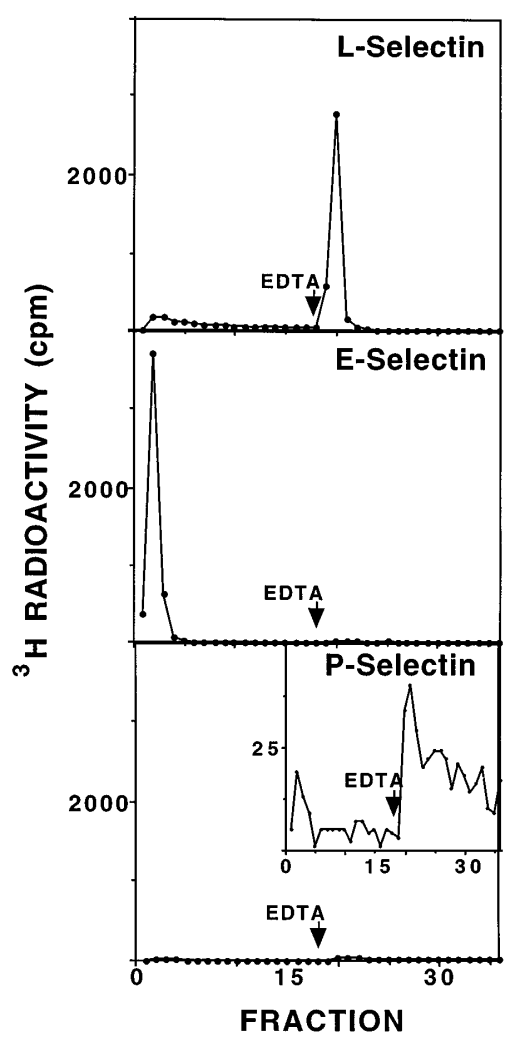

Figure 1. CPAE and HUVEC HS chains can bind to L- and P-selectin, but not to E-selectin. Aliquots of $\left[{ }^{3} \mathrm{H}\right] \mathrm{GlcNH}_{2}$-labeled CPAE HS chains that originally bound to L-selectin were desalted and reapplied to L-, E-, and P-selectin affinity columns in which each of the three selectin chimeras were immobilized on PAS beads at similar densities $(0.5$ $\mathrm{mg} / 0.5 \mathrm{ml})$. After washing, the bound ligand was eluted with $5 \mathrm{mM}$ EDTA, as described in Methods. Fractions were collected and monitored for radioactivity. Similar results were obtained with the HS chains from HUVEC cells (data no shown). In both cases, the radioactivity eluted very slowly and incompletely from the

P-selectin column (see bottom panel for an example). After both runs were completed, the P-selectin column was washed again with $20 \mathrm{mM}$ EDTA, which caused elution of all of the bound radioactivity from both runs (data not shown).

deed, as shown in Fig. 2, binding to L-selectin is abolished in $\mathrm{Mg}^{2+} /$ EGTA buffers, in which calcium is lowered to negligible amounts (effective $\mathrm{Ca}^{2+}$ concentration $0.774 \mathrm{nM}, \mathrm{Mg}^{2+}$ concentration $\sim 3 \mathrm{mM}$ ). The calcium dependence of this interaction is further indicated by the fact that as little as $0.5 \mathrm{mM}$ EDTA can efficiently elute the HS chains from an L-selectin column (data not shown). In striking contrast to the observations with L-selectin, binding of these same HS chains to P-selectin occurred efficiently even in the magnesium/EGTA buffer (Fig. 2, bottom), indicating that it does not require exogenously added calcium. Since the binding of the HS chains to P-selectin occurred in the presence of either calcium or magnesium, we next asked if this required any exogenously added cations for binding. Fig. 3 demonstrates that binding is supported by P-selectin without any exogenously added cations; however, the ligand was still eluted by using $20 \mathrm{mM}$ EDTA. This raises two possibilities: one is that there are trace amounts of calcium which remain tightly bound to the selectin column from the prior experiments; the other is that EDTA was eluting the ligand from P-selectin by a mechanism unrelated to its divalent cation chelating properties. The first possibility is somewhat unlikely, based on the available data on the crystal structures of E-selectin (83) and the related C-type lectin mannose binding protein (86) in both of which the calcium ion is exposed to the solvent and does not lie deeply buried in the binding pocket. In support of the second possibility, the elution of P-selectin by high concentrations of EDTA is not due simply 


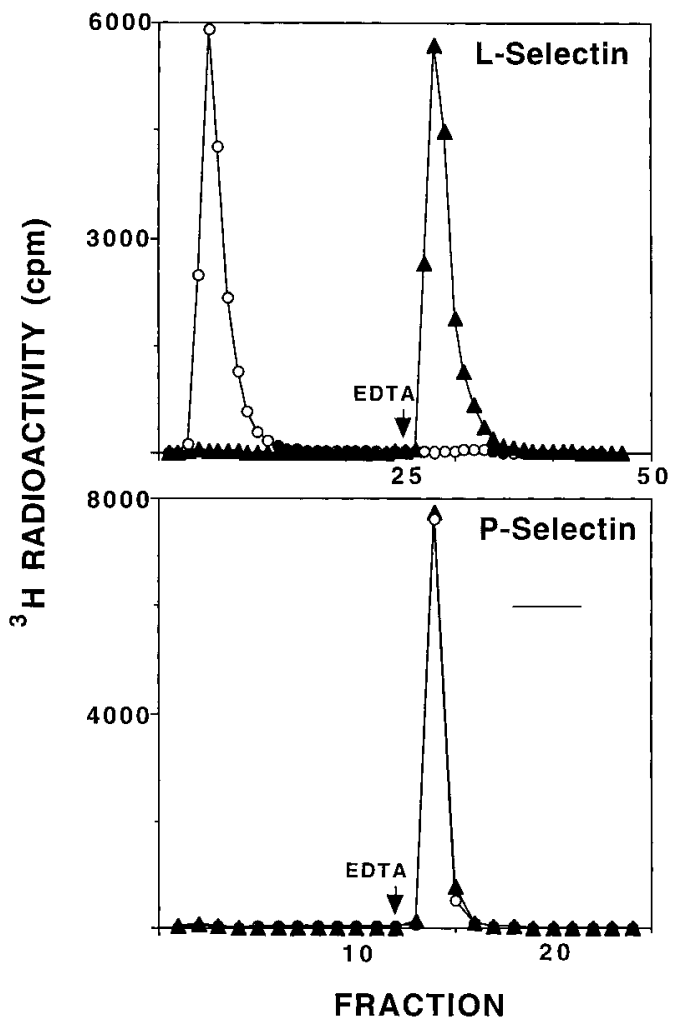

Figure 2. L-selectin binding of the HS-GAG chains is calcium dependent while P-selectin binding is not. Aliquots of HS chains which previously bound to an L-selectin column were reapplied either to the same column, or to a column of P-selectin, either in the presence of $5 \mathrm{mM}$ calcium (filled triangles) or in a magnesium/EGTA buffer (open circles) giving a residual free calcium concentration of $\sim 800$ $\mathrm{pM}$. The columns were washed with the same buffers, and then eluted with either $5 \mathrm{mM}$ EDTA for L-selectin or $20 \mathrm{mM}$ EDTA for P-selectin. Fractions were collected and radioactivity was monitored.

to its ionic strength, since an equivalent $(80 \mathrm{mM})$ increase in chloride concentration did not cause elution (data not shown). Thus, we suggest that EDTA might be eluting the ligands by virtue of its inherent polycarboxylate structure rather than its ability to chelate cations, i.e., that it might mimic the high charge density of HS chains. This hypothesis requires further investigation.

PIM-heparin shows similar, but not identical, binding to the selectins. The endothelial HS chains are available in limited quantities and are thus difficult to characterize further. Therefore, we studied commercially available PIM (mast cell-derived) heparin in a similar manner. Furthermore, the latter is also of interest since it is used for therapeutic purposes in humans as an anticoagulant. To monitor binding of PIM-heparin to the selectins, we radiolabeled the reducing end of the large heparin chains in this preparation by reduction with $\mathrm{NaB}\left[{ }^{3} \mathrm{H}\right]_{4}$. Based on our other recent studies, the salt concentrations in the column buffer were also adjusted to more closely approximate physiological conditions (77). Also, based on the results described above, bound material was eluted first with $2 \mathrm{mM}$ EDTA (divalent cation-dependent component), and then with $20 \mathrm{mM}$ EDTA (divalent cation-independent component, EDTA acting as a polycarboxylate). As shown in Fig. 4, none



Figure 3. P-selectin binding of the HS-GAG chains does not require exogenously added cations. An aliquot of the HS-GAG ligand that had previously bound to an L-selectin column was extensively dialyzed against water and then adjusted into buffer containing $100 \mathrm{mM}$ $\mathrm{NaCl}, 20 \mathrm{mM}$ Mops (pH 7.4). The P-selectin column was washed and allowed to sit in $20 \mathrm{mM}$ EDTA overnight at $4^{\circ} \mathrm{C}$ before extensive washing with the $100 \mathrm{mM} \mathrm{NaCl}, 20 \mathrm{mM}$ Mops (pH 7.4). The HSGAG aliquot was then applied to the P-selectin column and again washed with the same buffer (thus, no exogenous cations were added or present in either the loading or washing of this column run). The column was then eluted with $20 \mathrm{mM}$ EDTA. Fractions were collected and radioactivity was monitored.

of the PIM-heparin molecules bound to E-selectin. A significant fraction of the molecules (58\%) bound to L-selectin and were partially eluted with $2 \mathrm{mM}$ EDTA; the remainder (32\%) was eluted with the $20 \mathrm{mM}$ EDTA. In contrast, while a similar total fraction $(79 \%)$ of the total heparin bound to P-selectin, very little was eluted upon calcium chelation with $2 \mathrm{mM}$ EDTA. Instead, extensive washing with $20 \mathrm{mM}$ EDTA was required to elute all of the bound radioactive heparins from P-selectin. Thus, the behavior of the PIM-heparin toward the selectins appeared similar to that of the HS chains from endothelial cells, except that a fraction of the heparin remained bound to L-selectin after adding $2 \mathrm{mM}$ EDTA.

We next investigated the $\mathrm{Ca}^{2+}$ dependence of heparin binding to L- and P-selectin. As shown in Fig. 5, the results were again similar, but not identical, to those obtained with endothelial HS chains. Binding to L-selectin is abolished in $\mathrm{Mg}^{2+}$ / EGTA buffers, in which calcium is present in negligible amounts, while a significant fraction continued to bind to P-selectin under these conditions (Fig. 5, bottom). However, the actual fraction binding to P-selectin (45\%) was significantly lower than that seen under calcium-replete conditions (see Fig. 4, 79\%), indicating a partial calcium dependency of the initial binding phenomenon. Of the fraction that did bind in the absence of calcium, $20 \mathrm{mM}$ EDTA was still required for elution (Fig. 5, bottom). Taken together, these data seem to indicate that calcium occupancy in the lectin site may assist the initial binding of some heparin fragments to P-selectin. However, once bound, calcium is no longer required to maintain the interaction of the heparin chains to P-selectin.

Binding of size-defined heparin fragments to $L$ - and P-selectin. The PIM-heparin chains are of large molecular masses (average $\sim 20 \mathrm{kD}, \sim 38-40$ disaccharide units) and are poly- 


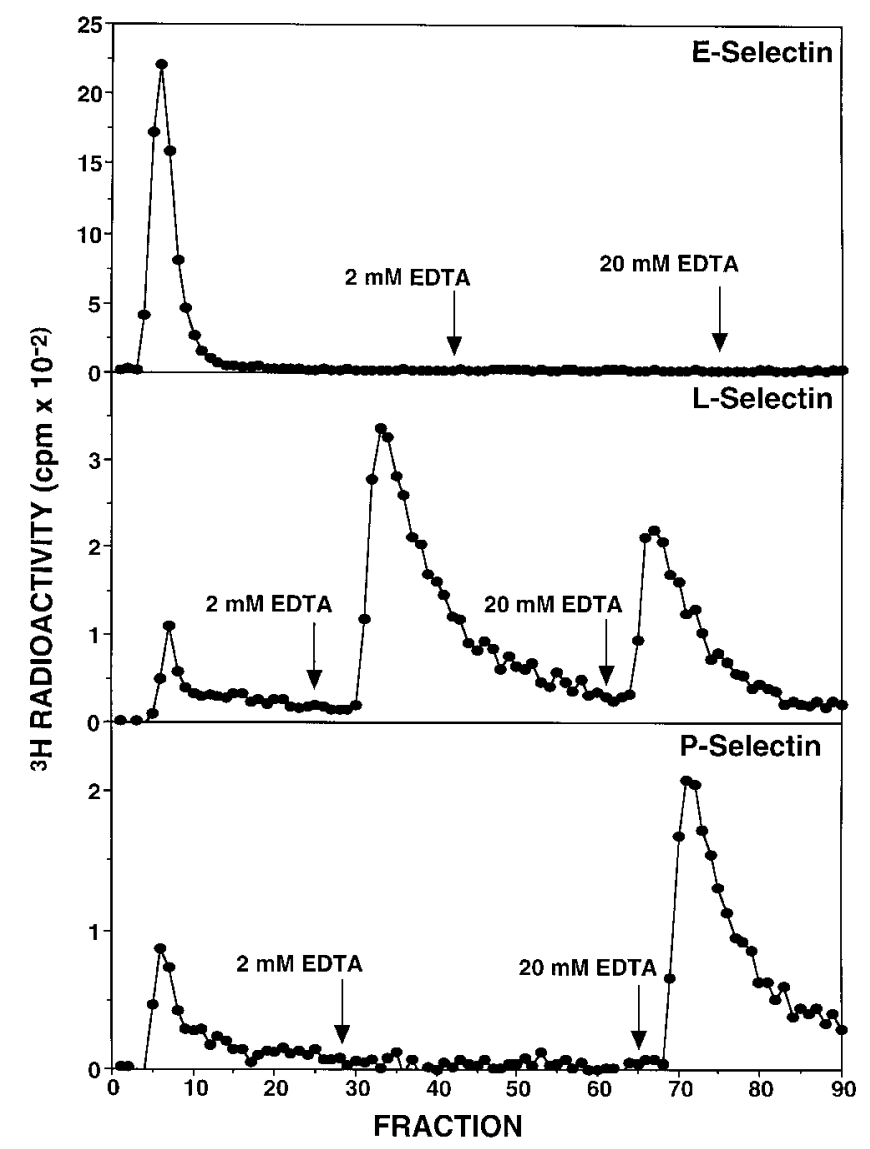

Figure 4. Fractions of PIM-heparin can bind to L- and P-selectin, but not to E-selectin. Aliquots of ${ }^{3} \mathrm{H}$-labeled PIM-heparin were applied to L-, E-, and P-selectin affinity columns in which each of the three selectin chimeras were immobilized on PAS beads at similar densities $(0.5 \mathrm{mg} / 0.5 \mathrm{ml})$. After washing, the bound ligand was eluted first with $2 \mathrm{mM}$ EDTA, and then with $20 \mathrm{mM}$ as described in Methods. Fractions were collected and monitored for radioactivity. For the E-selectin: $100 \%$ of the material ran through; for L-selectin: $10 \%$ ran through, $58 \%$ eluted with $2 \mathrm{mM}$ EDTA, and $32 \%$ eluted with $20 \mathrm{mM}$ EDTA; for P-selectin: $21 \%$ ran through, little to no material eluted with $2 \mathrm{mM}$ EDTA, and $79 \%$ eluted with $20 \mathrm{mM}$ EDTA. Percentages are the average of three to four chromatography experiments.

disperse in structure (73). Also, a variable fraction of commercial heparin fragments still has an attached peptide at the reducing terminus which would not have been labeled by $\mathrm{NaB}\left[{ }^{3} \mathrm{H}\right]_{4}$ reduction. Finally, it is possible that some of the binding is due to multivalent interactions with many low-affinity sites on the long heparin chain, involving multiple selectin molecules. To explore a better definable interaction, we studied the binding of size-fractionated heparin fragments (73) to the selectin columns. As before, the fractions were first labeled by reduction with $\mathrm{NaB}\left[{ }^{3} \mathrm{H}\right]_{4}$ to monitor the elution profiles easily. As shown in Fig. 6 and Table I, the binding of these $\left[{ }^{3} \mathrm{H}\right]$ heparin fragments to L- and P-selectin is size dependent, with substantial binding only seen with tetradecasaccharides. Others have previously reported interactions of heparin tetrasaccharides with L-selectin in blocking binding to immobilized SLe ${ }^{\mathrm{x}}$ (53), a well-known component of natural selectin ligands. Under the conditions of affinity column chromatography used here, binding constants in the low micromolar range would be needed for detection of binding $(87,88)$. Indeed, as shown in Table II, the tetradecasaccharides have IC $_{50}$ values for inhibition of L-and P-selectin interactions with SLe ${ }^{\mathrm{x}}$ that are in the low micromolar range. It is interesting to note that this tetradecasaccharide mixture gave $\mathrm{IC}_{50}$ values that are $\sim 10$-fold superior to those reported for SLe ${ }^{\mathrm{x}}$ itself (tetradecasaccharides: 82 and $54 \mu \mathrm{M}$ for P- and L-selectin, respectively; and SLe ${ }^{\mathrm{x}}, 520$ and 600 for P- and L-selectin, respectively [77]).

Given the size of the tetradecasaccharides relative to that of the selectin lectin domain (83), these interactions are likely to represent monovalent recognition by the selectin-Rg chimeras (note that the tetradecasaccharides were generated by partial heparin lyase I degradation and reduced with borohydride, thus, the first, or nonreducing monosaccharide unit has a nonnative $\mathrm{C} 4-\mathrm{C} 5$ double bond, and the last unit has an open ring). The divalent cation dependence of this interaction was also similar with that of intact heparin and the endothelial HS chains. Again, the interactions with L-selectin are disrupted by 2 mM EDTA (divalent cation chelation); most of those with P-selectin require $20 \mathrm{mM}$ EDTA for elution (although a small fraction is eluted with $2 \mathrm{mM}$ EDTA in a reproducible fashion,

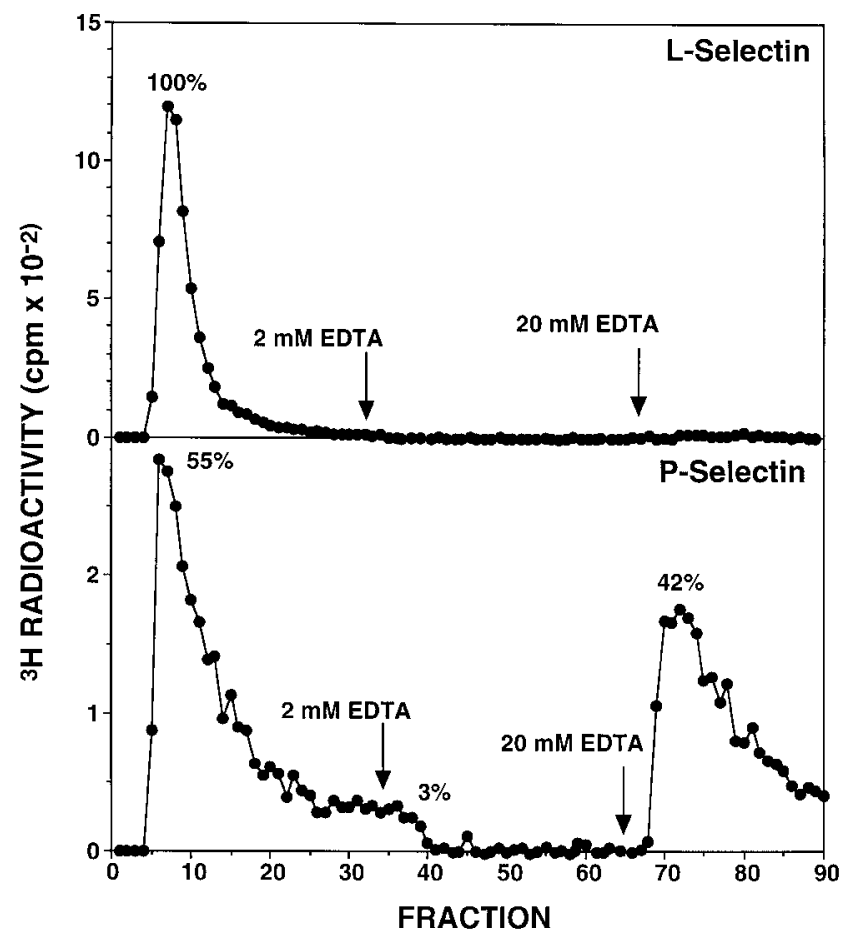

Figure 5. Binding of PIM-heparin to L-selectin is calcium dependent. Aliquots of ${ }^{3} \mathrm{H}$-labeled PIM-heparin were applied to L- and P-selectin affinity columns in a magnesium/EGTA buffer that gives a residual free calcium concentration of $\sim 800 \mathrm{pM}$. The columns were washed with the same buffer and eluted first with $2 \mathrm{mM}$ EDTA, and then with $20 \mathrm{mM}$ as described in Methods. Fractions were collected and monitored for radioactivity. For the L-selectin column, 100\% of the material ran through the column; for P-selectin: $55 \%$ ran through, $3 \%$ eluted with $2 \mathrm{mM}$ EDTA, and $42 \%$ eluted with $20 \mathrm{mM}$ EDTA. Percentages are the average of two chromatography experiments. 


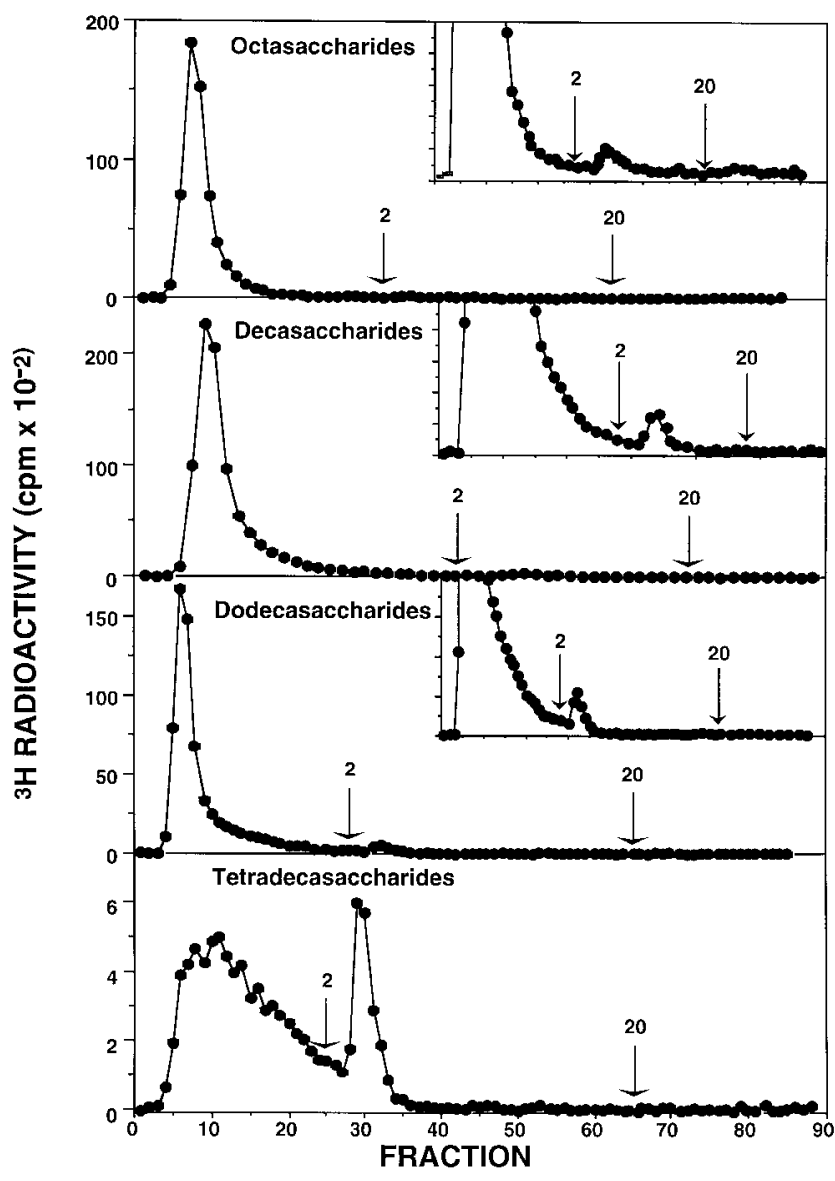

Figure 6. Size dependence of PIM-heparin fragments in binding to an $\mathrm{L}$-selectin affinity column. Aliquots of ${ }^{3} \mathrm{H}$-labeled PIM-heparin fragments were applied to an L-selectin affinity column. After washing, the bound ligand was eluted first with $2 \mathrm{mM}$ EDTA and then with $20 \mathrm{mM}$ (referred to as 2 and 20 in the figure, respectively) as described in Methods. Fractions were collected and monitored for radioactivity. Examples are shown of studies with octa-, deca-, dodeca-, and tetradecasaccharides. More detailed results, as well as the results of similar studies with P-selectin, are reported in Table I.

see Table III). Also, studies with $\mathrm{Mg}^{2+}$ /EGTA buffers confirmed the calcium requirement for L-selectin binding only (data not shown). The crystal structure of the closely related molecule E-selectin (83) indicated that the putative carbohydrate-binding region of the lectin domain is located on the opposite face away from the EGF domain. Thus, despite the lack of calcium dependence of binding of the tetradecasaccharides to $\mathrm{P}$-selectin, it is reasonable to suggest that these molecules may be binding somewhere relatively close to the calciumdependent binding site for SLe ${ }^{\mathrm{x}}$.

With the availability of a size-defined fraction, the binding of some molecules and the lack of binding of others become more meaningful. Thus, we fractionated the tetradecasaccharide fragments into bound and unbound fractions for both Land P-selectin (see Methods). As shown in Fig. 7 and Table III, rechromatography of these fractions confirmed that their behavior is reproducible. This indicates that specific structural features must determine the differential binding and that various populations differ over a wide range in their ability to in-
Table I. Effect of Size on the Binding of Heparin Fragments to $L$ - and P-selectin Affinity Columns

\begin{tabular}{lccc}
\hline & $\begin{array}{c}\text { L-selectin bound, } \\
\text { eluted with } \\
\text { 2 mM EDTA }\end{array}$ & $\begin{array}{c}\text { P-selectin bound, } \\
\text { eluted with } \\
\text { 2 mM EDTA }\end{array}$ & $\begin{array}{c}\text { P-selectin bound, } \\
\text { eluted with } \\
\text { 20 mM EDTA }\end{array}$ \\
\hline Tetradecasaccharides & $37 \%$ & $14 \%$ & $50 \%$ \\
Dodecasaccharides & $10 \%$ & $8 \%$ & $2.3 \%$ \\
Decasaccharides & $5 \%$ & $4 \%$ & $1 \%$ \\
Octasaccharides & $3 \%$ & $3 \%$ & $1.4 \%$
\end{tabular}

Sized mixtures of PIM-heparin fragments were ${ }^{3} \mathrm{H}$-labeled at the reducing end by $\mathrm{NaB}\left[{ }^{3} \mathrm{H}\right]_{4}$ reduction, as described in Methods. About 3,000 cpm of each of the labeled mixtures was dissolved into $200 \mu \mathrm{l}$ of the loading buffer and subjected to selectin affinity chromatography as described in Methods (see Fig. 6 for an example). None of the samples bound to the E-selectin column. All of the label bound to the L-selectin column eluted with $2 \mathrm{mM}$ EDTA, whereas most that bound to the P-selectin column required $20 \mathrm{mM}$ EDTA for elution.

teract with L-selectin. To pursue this matter further, we tried cross-binding studies. As shown in Table III, of the tetradecasaccharides that bind to L-selectin, $100 \%$ bound to P-selectin, and could only be eluted with $20 \mathrm{mM}$ EDTA. In contrast to those that bound to P-selectin, only a subfraction bound to L-selectin: $22 \%$ of the $2 \mathrm{mM}$ EDTA-eluted and $51 \%$ of the 20 $\mathrm{mM}$ EDTA-eluted material. Of the fraction that did not bind to L-selectin, $12 \%$ rebound to P-selectin, again, eluting off of the column only with $20 \mathrm{mM}$ EDTA. Finally, the fraction that did not bind P-selectin initially also did not bind to L-selectin. These data indicate that while both selectins have some degree of selectivity in recognizing heparin tetradecasaccharides, P-selectin has a more permissive range of recognition.

Table II. Heparin Fragment Mixtures as Inhibitors of L-and $P$-selectin binding to Immobilized $S L e^{x}$

\begin{tabular}{lrr}
\hline & \multicolumn{2}{c}{$\mathrm{IC}_{50}$ value } \\
\cline { 2 - 3 } & \multicolumn{1}{c}{ L-selectin } & \multicolumn{1}{c}{ P-selectin } \\
\hline Tetradecasaccharides & $54 \mu \mathrm{M}$ & $82 \mu \mathrm{M}$ \\
Dodecasaccharides & $159 \mu \mathrm{M}$ & $159 \mu \mathrm{M}$ \\
Decasaccharides & $1900 \mu \mathrm{M}$ & $>1900 \mu \mathrm{M}$ \\
Octasaccharides & $>2400 \mu \mathrm{M}$ & $>2400 \mu \mathrm{M}$ \\
SLe $^{\mathrm{x}}$ & $600 \mu \mathrm{M}$ & $520 \mu \mathrm{M}$
\end{tabular}

Size-fractionated PIM-heparin mixtures were tested for their ability to inhibit selectin binding to immobilized SLe ${ }^{\mathrm{x}}$ in ELISA inhibition experiments, as described in Methods. There was no inhibition of E-selectin, even with the tetradecasaccharides, at concentrations as high as $5 \mathrm{mg} / \mathrm{ml}$ $(>1,000 \mu \mathrm{M}) . \mathrm{IC}_{50}$ values for L- and P-selectin inhibition were determined by the equation: [(average of duplicates) - (average of negative controls $)] /[$ (average of positive controls) - (average of negative controls $)] \times 100$, where the positive controls were without inhibitors, and the negative controls contained $5 \mathrm{mM}$ EDTA. Experiments were performed two to three times, and the averaged $\mathrm{IC}_{50}$ values are presented. For calculation of concentration, the following average molecular masses were assumed: tetradecasaccharide, 3,675 D; dodecasaccharide, 3,150 D; decasaccharide, 2,625 D; and octasaccharides, 2,100 D. The inhibitory potency of the tetrasaccharide $\mathrm{SLE}^{\mathrm{x}}$ under the same conditions is shown for comparison. 


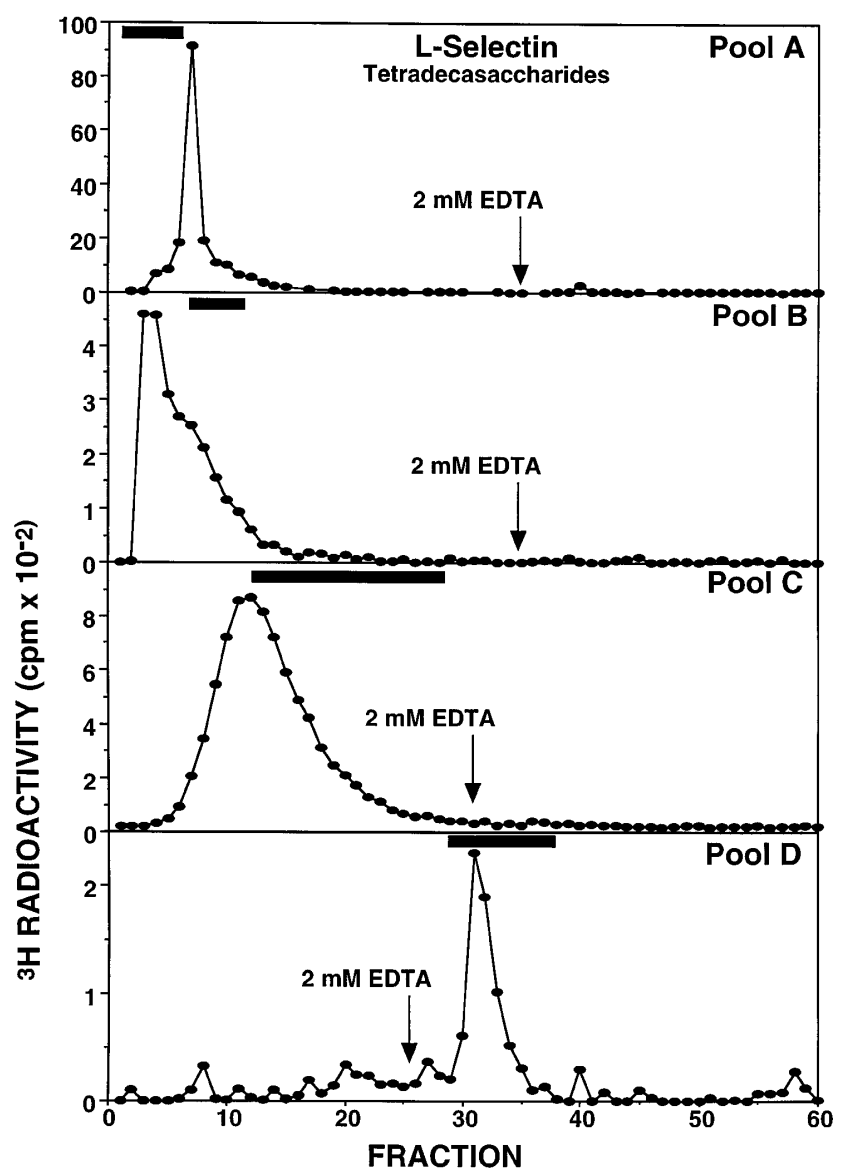

Figure 7. Examples of rechromatography of PIM-heparin tetradecasaccharides on an L-selectin affinity column. Aliquots of ${ }^{3} \mathrm{H}$-labeled PIM-heparin tetradecasaccharides that were originally unbound (Pool A), slightly retarded (Pool B), retarded (Pool C), or eluted with EDTA (Pool D) from an L-selectin affinity column were desalted and restudied on the same column. After washing with buffer, the columns were eluted with $2 \mathrm{mM}$ EDTA. Fractions were collected and monitored for radioactivity. The bar above each chromatogram indicates where the material originally eluted from the column. The results of cross-binding studies between P- and L-selectin bound and unbound fractions are also shown in Table III.

Analysis of the structural features on $\left[{ }^{3} H\right]$ tetradecasaccharides that determine binding behavior to $P$ - and L-selectin. These tetradecasaccharides are known to be a complex mixture, containing many different structural variations and isomers (73). Since size is not a variable, the differential binding of these molecules is likely due to some of these structural differences. To pursue this, aliquots of bound and unbound material from the P- and L-selectin columns were subjected to cleavage either with specific heparin lyases (I, II, and III), or by HONO treatment at $\mathrm{pH} 1.5$ or 4.0. Each of these treatments can cleave heparin chains, depending upon specific structural features or modifications $(72,78-81)$. The treated samples were analyzed by FPLC as described in Methods to evaluate the extent of cleavage (detailed data not shown). The conclusion is that L-selectin binding fragments include the more heavily sulfated and epimerized regions (sensitive to heparin lyase I and HONO, pH 1.5). Furthermore, as with the endo-
Table III. Rebinding and Cross-binding of

Tetradecasaccharides to L-and P-selectin

\begin{tabular}{|c|c|c|c|c|c|}
\hline \multirow[b]{2}{*}{ Secondary binding } & \multicolumn{5}{|c|}{ Original binding of sample } \\
\hline & $\begin{array}{l}\text { L-selectin } \\
\text { unbound }\end{array}$ & $\begin{array}{c}\text { L-selectin } \\
2 \mathrm{mM} \\
\text { EDTA } \\
\text { eluted }\end{array}$ & $\begin{array}{l}\text { P-selectin } \\
\text { unbound }\end{array}$ & $\begin{array}{c}\text { P-selectin } \\
2 \mathrm{mM} \\
\text { EDTA } \\
\text { eluted }\end{array}$ & $\begin{array}{c}\text { P-selectin } \\
20 \mathrm{mM} \\
\text { EDTA } \\
\text { eluted }\end{array}$ \\
\hline \multicolumn{6}{|l|}{ L-selectin } \\
\hline Unbound & $98 \%$ & $0 \%$ & $100 \%$ & $78 \%$ & $49 \%$ \\
\hline 2 mM EDTA eluted & $2 \%$ & $100 \%$ & $0 \%$ & $22 \%$ & $51 \%$ \\
\hline \multicolumn{6}{|l|}{ P-selectin } \\
\hline Unbound & $88 \%$ & $0 \%$ & $88 \%$ & $0 \%$ & $0 \%$ \\
\hline 2 mM EDTA eluted & $0 \%$ & $0 \%$ & $5 \%$ & $100 \%$ & $0 \%$ \\
\hline $20 \mathrm{mM}$ EDTA eluted & $12 \%$ & $100 \%$ & $7 \%$ & $0 \%$ & $100 \%$ \\
\hline
\end{tabular}

$\left[{ }^{3} \mathrm{H}\right]$-Labeled tetradecasaccharides were fractionationed by P- and L-selectin affinity chromatography as descrinbed in Methods. After desalting, aliquots of each fraction were reapplied to the same column, or to the other selectin column (see Fig. 7 for an example of the results).

thelial HS chains, these heparin tetradecasaccharide chains are enriched in the small amounts of free amino groups present in the mixture (sensitive to HONO, pH 4.0). The P-selectin binding component includes this fraction, as well as some less heavily modified regions sensitive to heparin lyase III. Overall, while distinct structural features seem to selectively enhance interactions of P- and L-selectin with heparin tetradecasaccharides, binding seems to represent a continuum of affinities, and no single structural motif is clearly superior in its ability to be recognized. Thus, we chose not to pursue a more detailed elucidation of the precise structure of the various fractions, but instead examined the clinical relevance of these observations.

Heparin inhibits $L$-and P-selectin binding at therapeutically relevant concentrations. The commercially purchased PIMheparin studied above is very similar to the material commonly used as an anticoagulant in routine clinical practice (61, $62,71)$. It is known that the plasma concentrations achieved during therapeutic anticoagulation can be as high as $1-4 \mu \mathrm{g} / \mathrm{ml}$ (61). We found that crude commercial PIM-heparin gave $\mathrm{IC}_{50}$ values of 2 and $18 \mu \mathrm{g} / \mathrm{ml}$ for SLe ${ }^{\mathrm{x}}$-binding of P- and L-selectin, respectively (data not shown), indicating that inhibition may be occurring at therapeutically relevant concentrations. To more closely approximate the clinical situation, we studied the inhibitory properties of pharmaceutical heparin samples as actually formulated for clinical use. The concentration in such preparations is reported as protamine neutralization units, which take into account the heterogeneity of individual heparin lots. As shown in Fig. 8 and Table IV, two separate lots of pharmaceutical unfractionated heparin gave significant inhibition of L- and P-selectin (but not E-selectin) at concentrations well within the recommended therapeutic range for anticoagulation $\left(\mathrm{IC}_{50}\right.$ values of $0.01-0.02$ and $0.07-0.08 \mathrm{U} / \mathrm{ml}$ toward $\mathrm{SLe}^{\mathrm{x}}$-binding of $\mathrm{P}$ - and L-selectin, respectively). To more closely approach the physiological situation in vivo, we next studied the effects of heparin on the binding of HL-60 cells to L- and P-selectin, which is known to be mediated by the natural ligand PSGL-1 (13-15, 18-20). As shown in Fig. 9 and Table IV, unfractionated heparin is an excellent inhibitor of this interaction, with $\mathrm{IC}_{50}$ values $\sim 12$ - and 50 -fold lower than the 


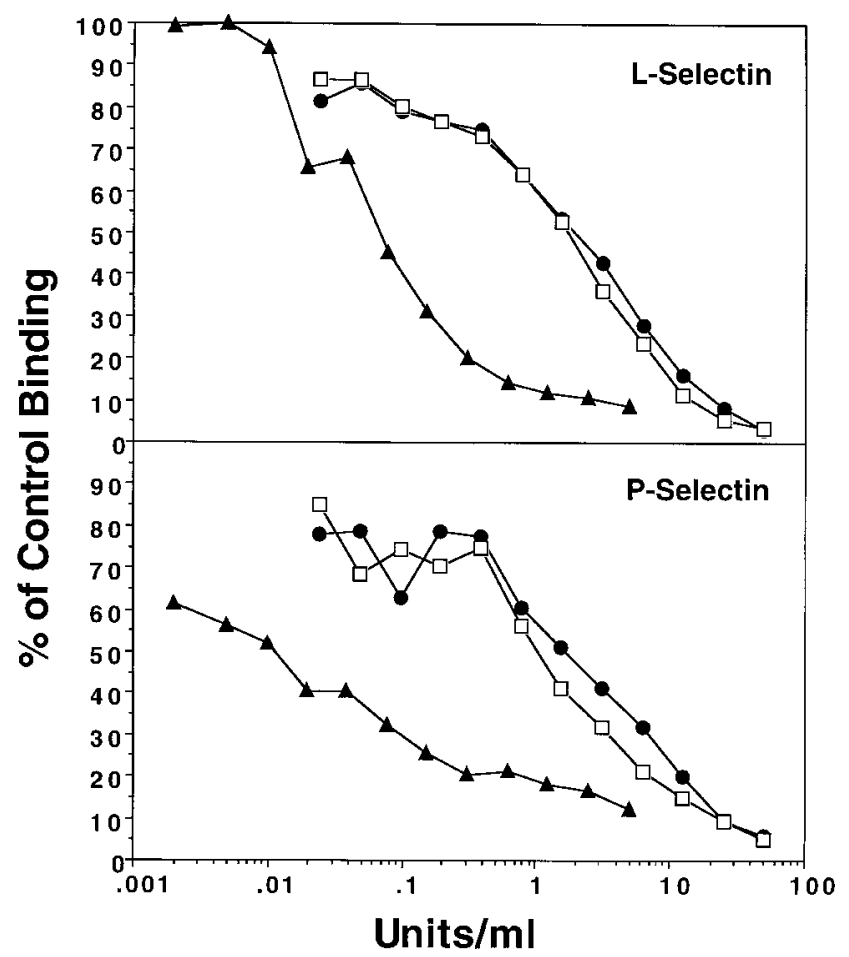

Figure 8. Inhibitory properties of clinical samples of unfractionated or LMW heparins on the binding of L- and P-selectin to immobilized $\mathrm{SLe}^{\mathrm{x}}$. Unfractionated heparin (filled triangles) or LMW heparins (Lovenox, open boxes, and Fragmin, filled circles) were tested for their ability to inhibit the binding of each of the recombinant selectins to immobilized SLe ${ }^{\mathrm{x}}$ in ELISA inhibition experiments, as described in Methods. The $\mathrm{IC}_{50}$ values from such studies are presented in $\mathrm{Ta}$ ble IV.

recommended therapeutic range, for $\mathrm{L}$ - and $\mathrm{P}$-selectin, respectively.

Comparison of inhibitory potency of heparin with LMW heparins. In recent years, clinical usage of unfractionated heparin has partly given way to the use of various pharmaceutical



Figure 9. Inhibition of HL-60 cell binding to immobilized L-selectin (open boxes) and P-selectin (filled circles) with unfractionated heparin. Unfractionated heparin was tested for its ability to inhibit the binding of ${ }^{3} \mathrm{H}$-labeled HL-60 cells to immobilized L- and P-selectin. The $\mathrm{IC}_{50}$ values from such studies are presented in Table IV, along with similar data for the LMW heparins. The black bar shows the recommended plasma concentration range for the therapeutic use of unfractionated heparin as an anticoagulant.

preparations of LMW heparins $(61,62,67,71,89)$. These preparations are characterized by enhanced bioavailability and half-life as well as a somewhat decreased incidence of toxicities $(61,71)$. In addition, their anticoagulant activity is measured in anti-Xa units rather than as protamine neutralization units. As shown in Fig. 8 and Table IV, two different types of clinical grade LMW heparins (Fragmin and Lovenox) gave $\mathrm{IC}_{50}$ values against L- and P-selectin that were at or higher than the recommended therapeutic levels, both in ELISA inhibition experiments against immobilized SLe ${ }^{\mathrm{x}}$ and in HL-60 cell binding inhibition experiments. Thus, two LMW heparins that are currently considered appropriate clinical replacements for unfrac-

Table IV. Unfractionated and LMW Heparins as Inhibitors of L-and P-selectin Binding to Immobilized SLe $e^{x}$ and to $\left[{ }^{3} \mathrm{H}\right] \mathrm{HL}-60$ Cells

\begin{tabular}{|c|c|c|c|c|c|c|}
\hline \multirow[b]{3}{*}{ Clinical heparin } & \multirow[b]{3}{*}{$\begin{array}{l}\text { Therapeutic } \\
\text { range }\end{array}$} & \multicolumn{5}{|c|}{$\mathrm{IC}_{50} \mathrm{U} / \mathrm{ml} *$} \\
\hline & & \multicolumn{3}{|c|}{ Against immobilized SLe $\mathrm{e}^{\mathrm{x}}$} & \multicolumn{2}{|c|}{ Against HL-60 cells } \\
\hline & & E-selectin & L-selectin & P-selectin & L-selectin & P-selectin \\
\hline & $U / m l^{*}$ & & & & & \\
\hline Unfractionated heparin & $0.2-0.4$ & $>50$ & $0.07-0.08$ & $0.01-0.02$ & $0.02-0.03$ & $0.003-0.01$ \\
\hline Lovenox (LMW heparin, enoxaparin) & $0.6-1.0$ & $>50$ & $0.8-1.5$ & $0.8-1.0$ & $1.5-3.0$ & 0.7 \\
\hline Fragmin (LMW heparin, deltaparin) & $0.6-1.0$ & $>50$ & $0.7-2.0$ & $1.5-2.0$ & $4.0-7.0$ & $1.0-4.0$ \\
\hline
\end{tabular}

Several clinical lots of unfractionated and LMW heparins were tested for their ability to inhibit selectin binding to immobilized SLe ${ }^{\mathrm{x}}$ in ELISA inhibition experiments or HL-60 cells binding to immobilized selectins, as described in Methods. $\mathrm{IC}_{50}$ values were determined by the equation: [ $($ average of duplicates $)-($ average of negative controls $)] /[$ (average of positive controls $)-($ average of negative controls $)] \times 100$, where the positive controls were without inhibitors, and the negative controls contained $5 \mathrm{mM}$ EDTA in the ELISA inhibition experiments, and $20 \mathrm{mM}$ EDTA in the HL-60 cell inhibition experiments. Experiments were performed two to three times, and the range of measured $\mathrm{IC}_{50}$ values is presented. Examples of the results can be seen in Figs. 8 and 9. *Unfractionated heparin concentrations are reported in protamine neutralization units while LMW heparins are reported as anti-Xa units (see text for discussion). 
tionated heparin are much poorer inhibitors of L- and P-selectin binding to sialylated ligands, including PSGL-1.

\section{Discussion}

Prior work had shown that L- and P-selectin binding are similar to each other (and different from E-selectin) in their ability to be inhibited by many compounds containing sulfate groups (47-56). However, given the broad range of natural and artificial sulfated molecules that showed such effects, it was assumed that there was relatively little specificity to these interactions. Subsequently, we found that certain subfractions of endothelial cell HS-GAG chains bind to L-selectin in a calcium-dependent manner $(57,58)$, and suggested that these interactions might be of biological relevance. Very recently, others have shown directly that HS chains expressed on cultured bovine aortic endothelial cells can indeed act as functional ligands for L-selectin (60). We have demonstrated here that these endothelial HS chains also bind to P-selectin, but not to E-selectin. The results indicate that while there may be some overlap in the binding specificities of P- and L-selectin for HS chains, there are distinct differences. This is encouraging from the point of view of trying to develop inhibitors that might selectively interrupt the binding function of one selectin or the other in various in vivo situations. It would also be of interest to know if selectin interactions could explain previous reports of specific interactions of heparin with neutrophils $(90,91)$, or with platelets (92-95).

In previous studies involving $\mathrm{P}$ - and L-selectin, other investigators have observed "partial" effects of EDTA in blocking interactions with certain ligands (52). Our observation that the elution of the HS chain ligands from P-selectin column requires high concentrations of EDTA falls in this category. One possible explanation is that EDTA in this instance is functioning as a polycarboxylate rather than as a chelator of cations. In keeping with this, the initial binding of these HS chains to P-selectin does not appear to require calcium. However, direct competition studies suggest that the heparin interaction may involve a region of the $\mathrm{P}$-selectin molecule very close to the lectin-binding site for SLe ${ }^{\mathrm{x}}$. In this regard, others have shown that heparin fragments as small as tetrasaccharides are capable of specifically blocking the interactions of L- and P-selectin with SLe ${ }^{\mathrm{x}}$-containing ligands (53). Taken together with the reported crystal structure of the closely homologous protein E-selectin (83) which indicates a lectin domain separated away from the EGF domain, it is reasonable to suggest that the HS and sialylated ligands might be both recognized in regions close to the lectin-binding site.

Almost all of the other reported ligands for L- and P-selectin are mucin-type glycoproteins $(3,13,19,20,37,38,85,96-$ 99). How can two such disparate carbohydrate structures as mucins (bearing clustered O-GalNAc-linked oligosaccharides with sialic acids, fucose and sulfates groups) and HS chains (bearing uronic acids and sulfated glucosamine residues on O-Xyl-linked proteins) be recognized by the same or similar binding site? One possibility we have suggested is that the recognition involves not a linear defined oligosaccharide sequence but a "clustered saccharide patch" that can be generated in multiple different ways $(3,37)$. Thus, a clustered patch with the appropriate arrangement of carboxyl groups, sulfate esters, and hydroxyl groups (and perhaps unsubstituted amino groups) might be generated either by the closely packed oli- gosaccharides in the mucins, or by the densely modified HSGAG chain. The present data support, but do not prove, this hypothesis.

Our results indicate that $\mathrm{P}$-selectin binds a large range of HS and heparin fragments, predominantly in a calcium-independent manner. L-selectin seems less promiscuous and may require a more specific sequence for recognition, since it requires $\mathrm{Ca}^{2+}$, and a significant fraction of the binding material was degraded upon treatment with HONO, $\mathrm{pH}$ 4.0. This is consistent with the previous finding of free amino groups on the HS chains that bind L-selectin (58). Overall, it appears that, while distinct structural features may selectively enhance interactions of P- and L-selectin with heparin tetradecasaccharides, binding represents a continuum of affinities, with no single structural motif being clearly superior. Thus, we chose not to pursue a more detailed elucidation of the precise structure of the various fractions at this time, but instead focused on the potential clinical relevance of these observations.

While $\mathrm{SLe}^{\mathrm{x}}$ and related structures hold great promise for therapeutic use in a variety of disease states $(2,18,39-44)$, they have a number of potential drawbacks. First, the apparent affinities of the selectins for $\mathrm{SLe}^{\mathrm{x}}$ are quite weak $(1,3,75)$. Second, the small size of the molecules would give a short circulating half-life. Third, there is a very limited track record in the use of sialylated oligosaccharides as intravenous therapeutic agents. Finally, SLe ${ }^{\mathrm{x}}$ is not expected to have much selectivity in its ability to block interactions by one or the other of the selectins. The ability of heparin chains to completely bind to an L-selectin affinity column indicates that their affinity is higher than that of oligosaccharides such as SLe ${ }^{\mathrm{x}}$, which do not show detectable binding under these conditions. This is supported by the $\mathrm{IC}_{50}$ values measured in in vitro assays. These facts, along with its established record of heparin as a therapeutic agent, encouraged us to consider if heparin is useful as a therapeutic for interfering with L- or P-selectin-based interactions.

Most prior studies of this type have used commercially available heparin preparations and studied inhibitory properties on a per weight basis $(47,48,50,53)$. Perhaps because of similar findings made with unnatural sulfated ligands such as dextran sulfate and fucoidan, and the well-known danger of bleeding from systemic anticoagulation, the effects of heparin on selectins that were noted had not been considered to be of practical importance. We decided to check if concentrations of heparin that are routinely achieved during its clinical use as an anticoagulant are capable of inhibiting selectin function. To be certain of the significance of our studies we used actual lots of heparin as formulated for clinical use. To our surprise, we found that the recommended target level for anticoagulation by unfractionated heparins is sufficient to cause essentially complete inhibition of both L- and P-selectin in an in vitro assay involving binding to $\mathrm{SLe}^{\mathrm{x}}$. Indeed, the $\mathrm{IC}_{50}$ values for this inhibition are $\sim 10$-fold less than the recommended levels for anticoagulation. Furthermore, similar findings were obtained in a HL-60 cell-binding assay which measures the interaction of L- and P-selectin with the natural ligand, PSGL-1 (13-15, 18-20). In this case, we found the $\mathrm{IC}_{50}$ values for P-selectin to be even lower ( $\sim 50$-fold less than the recommended therapeutic level). Many of the reperfusion injury situations in which inhibition of PSGL-1-based P- and L-selectin interactions are considered to be of potential value (stroke, myocardial ischemia, etc.) are already routinely treated with heparin, with the assumption that it will be of therapeutic value as an 
anticoagulant $(61,62,67,95)$. Thus, researchers and clinicians may have been already inadvertently achieving substantial degrees of partial selectin inhibition using a drug (heparin) that was already approved for another indication (anticoagulation). For example, it is interesting to note that the best effects of thrombolytic therapy for acute myocardial infarction are seen when heparin was included in the treatment regimen (100104). We wonder if, in such instances, heparin is working primarily by providing protection from $\mathrm{P}$ - and L-selectin-mediated reperfusion injury, rather than by its anticoagulant action. This logic may also partly explain the highly variable results of attempted selectin inhibition by SLe ${ }^{\mathrm{x}}$-related compounds in various experimental and clinical situations (40, 43, 105-109). Further attempts at clinical selectin inhibition should take into account this practical reality.

Another finding of immediate practical relevance is that the LMW heparins currently in vogue as preferred anticoagulants over unfractionated heparins (61-71) may not be achieving the same degree of selectin inhibition at the levels currently recommended for their use. Indeed, the $\mathrm{IC}_{50}$ values of these compounds against selectin-PSGL-1 interactions are so close to or even above the recommended target range for anticoagulation that the degree of selectin inhibition in a given patient would be hard to predict. This difference between unfractionated and LMW heparins is best explained by our in vitro finding that smaller sized fragments are less effective inhibitors. Alternatively, critical regions required for recognition may be disrupted during the various chemical and enzymatic processes used for fragmentation. In either case, the currently popular switchover from unfractionated to LMW heparins (66, $68,71)$ may come at a loss of this selectin inhibition effect. A final conclusion arising from this work is that low doses of unfractionated heparin should be explored as a treatment option for acute and chronic diseases in which $\mathrm{P}$ - and L-selectin are known to play pathophysiological roles such as bronchial asthma, rheumatoid arthritis, etc.

\section{Acknowledgments}

The authors thank Nahid Razi and Jeff Esko for helpful discussions and for their careful review of the manuscript.

This research was supported by grants RO1-CA38701 (to A. Varki), RO1-HL52622 (to R. Linhardt) and P50-HL 23594 (to K. Moser). A. Koenig was also supported by a training grant (T32 DK07202).

\section{References}

1. Bevilacqua, M.P., and R.M. Nelson. 1993. Selectins. J. Clin. Invest. 91: 379-387.

2. Albelda, S.M., C.W. Smith, and P.A. Ward. 1994. Adhesion molecules and inflammatory injury. FASEB (Fed. Am. Soc. Exp. Biol.) J. 8:504-512. 7397.

3. Varki, A. 1994. Selectin ligands. Proc. Natl. Acad. Sci. USA. 91:7390-

4. Furie, B., and B.C. Furie. 1995. The molecular basis of platelet and endothelial cell interaction with neutrophils and monocytes: role of P-selectin and the P-selectin ligand, PSGL-1. Thromb. Haemostasis. 74:224-227.

5. Lasky, L.A. 1995. Selectin-carbohydrate interactions and the initiation of the inflammatory response. Annu. Rev. Biochem. 64:113-139.

6. McEver, R.P., K.L. Moore, and R.D. Cummings. 1995. Leukocyte trafficking mediated by selectin-carbohydrate interactions. J. Biol. Chem. 270: 11025-11028.

7. Nelson, R.M., A. Venot, M.P. Bevilacqua, R.J. Linhardt, and I. Stamenkovic. 1995. Carbohydrate-protein interactions in vascular biology. Annu. Rev. Cell Biol. 11:601-631.

8. Springer, T.A. 1995. Traffic signals on endothelium for lymphocyte recir- culation and leukocyte emigration. Annu. Rev. Physiol. 57:827-872.

9. Tedder, T.F., D.A. Steeber, A. Chen, and P. Engel. 1995. The selectins vascular adhesion molecules. FASEB (Fed. Am. Soc. Exp. Biol.) J. 9:866-873.

10. Butcher, E.C., and L.J. Picker. 1996. Lymphocyte homing and homeostasis. Science. 272:60-66.

11. Crocker, P.R., and T. Feizi. 1996. Carbohydrate recognition systems: functional triads in cell-cell interactions. Curr. Opin. Struct. Biol. 6:679-691.

12. Hynes, R.O., and D.D. Wagner. 1996. Genetic manipulation of vascular adhesion molecules in mice. J. Clin. Invest. 98:2193-2195.

13. Kansas, G.S. 1996. Selectins and their ligands: current concepts and controversies. Blood. 88:3259-3287.

14. Rosen, S.D., and C.R. Bertozzi. 1996. Leukocyte adhesion: two selectins converge on sulphate. Curr. Biol. 6:261-264.

15. Vestweber, D. 1996. Ligand-specificity of the selectins. J. Cell. Biochem. 61:585-591.

16. Zimmerman, G.A., T.M. McIntyre, and S.M. Prescott. 1996. Adhesion and signaling in vascular cell-cell interactions. J. Clin. Invest. 98:1699-1702.

17. Frenette, P.S., and D.D. Wagner. 1997. Insights into selectin function from knockout mice. Thromb. Haemostasis. 78:60-64.

18. Lowe, J.B., and P.A. Ward. 1997. Therapeutic inhibition of carbohydrate-protein interactions in vivo. J. Clin. Invest. 99:822-826.

19. Varki, A. 1997. Selectin ligands: will the real ones please stand up? J. Clin. Invest. 99:158-162.

20. McEver, R.P., and R.D. Cummings. 1997. Role of PSGL-1 binding to selectins in leukocyte recruitment. J. Clin. Invest. 100:485-492.

21. Matsusako, T., H. Muramatsu, T. Shirahama, T. Muramatsu, and Y. Ohi. 1991. Expression of a carbohydrate signal, sialyl dimeric $\mathrm{Le}^{\mathrm{X}}$ antigen, is associated with metastatic potential of transitional cell carcinoma of the human urinary bladder. Biochem. Biophys. Res. Commun. 181:1218-1222.

22. Aruffo, A., M.T. Dietsch, H. Wan, K.E. Hellström, and I. Hellström. 1992. Granule membrane protein 140 (GMP140) binds to carcinomas and carcinoma-derived cell lines. Proc. Natl. Acad. Sci. USA. 89:2292-2296.

23. Nakamori, S., M. Kameyama, S. Imaoka, H. Furukawa, O. Ishikawa, Y. Sasaki, T. Kabuto, T. Iwanaga, Y. Matsushita, and T. Irimura. 1993. Increased expression of sialyl Lewis ${ }^{\mathrm{x}}$ antigen correlates with poor survival in patients with colorectal carcinoma: clinicopathological and immunohistochemical study. Cancer Res. 53:3632-3637.

24. Takada, A., K. Ohmori, T. Yoneda, K. Tsuyuoka, A. Hasegawa, M. Kiso, and R. Kannagi. 1993. Contribution of carbohydrate antigens sialyl Lewis A and sialyl Lewis $\mathrm{X}$ to adhesion of human cancer cells to vascular endothelium. Cancer Res. 53:354-361.

25. Ogawa, J., H. Inoue, and S. Koide. 1996. Expression of $\alpha-1,3$-fucosyltransferase type IV and VII genes is related to poor prognosis in lung cancer. Cancer Res. 56:325-329.

26. Nakamori, S., M. Kameyama, S. Imaoka, H. Furukawa, O. Ishikawa, Y. Sasaki, Y. Izumi, and T. Irimura. 1997. Involvement of carbohydrate antigen sialyl Lewis ${ }^{\mathrm{x}}$ in colorectal cancer metastasis. Dis. Colon Rectum. 40:420-431.

27. Phillips, M.L., E. Nudelman, F.C.A. Gaeta, M. Perez, A.K. Singhal, S Hakomori, and J.C. Paulson. 1990. ELAM-1 mediates cell adhesion by recognition of a carbohydrate ligand, sialyl-Le ${ }^{\mathrm{x}}$. Science. 250:1130-1132.

28. Walz, G., A. Aruffo, W. Kolanus, M. Bevilacqua, and B. Seed. 1990. Recognition by ELAM-1 of the sialyl-Le ${ }^{\mathrm{x}}$ determinant on myeloid and tumor cells. Science. 250:1132-1135.

29. Polley, M.J., M.L. Phillips, E. Wayner, E. Nudelman, A.K. Singhal, S Hakomori, and J.C. Paulson. 1991. CD62 and endothelial cell-leukocyte adhesion molecule 1 (ELAM-1) recognize the same carbohydrate ligand, sialylLewis x. Proc. Natl. Acad. Sci. USA. 88:6224-6228.

30. Berg, E.L., M.K. Robinson, O. Mansson, E.C. Butcher, and J.L. Magnani. 1991. A carbohydrate domain common to both sialyl Le $\mathrm{Le}^{\mathrm{a}}$ and sialyl $\mathrm{Le}^{\mathrm{X}}$ is recognized by the endothelial cell leukocyte adhesion molecule ELAM-1. $J$. Biol. Chem. 266:14869-14872.

31. Tyrrell, D., P. James, N. Rao, C. Foxall, S. Abbas, F. Dasgupta, M. Nashed, A. Hasegawa, M. Kiso, D. Asa, et al. 1991. Structural requirements for the carbohydrate ligand of E-selectin. Proc. Natl. Acad. Sci. USA. 88:1037210376.

32. Berg, E.L., J. Magnani, R.A. Warnock, M.K. Robinson, and E.C. Butcher. 1992. Comparison of L-selectin and E-selectin ligand specificities: the L-selectin can bind the E-selectin ligands sialyl $\mathrm{Le}^{\mathrm{x}}$ and sialyl Le ${ }^{\mathrm{a}}$. Biochem. Biophys. Res. Commun. 184:1048-1055.

33. Foxall, C., S.R. Watson, D. Dowbenko, C. Fennie, L.A. Lasky, M. Kiso, A. Hasegawa, D. Asa, and B.K. Brandley. 1992. The three members of the selectin receptor family recognize a common carbohydrate epitope, the sialyl Lewis $^{\mathrm{x}}$ oligosaccharide. J. Cell Biol. 117:895-902.

34. Larkin, M., T.J. A hern, M.S. Stoll, M. Shaffer, D. Sako, J. O'Brien, C.-T. Yuen, A.M. Lawson, R.A. Childs, K.M. Barone, et al. 1992. Spectrum of sialylated and nonsialylated fuco-oligosaccharides bound by the endothelial-leukocyte adhesion molecule E-selectin. Dependence of the carbohydrate binding activity on E-selectin density. J. Biol. Chem. 267:13661-13668.

35. Philips, M.L., B.R. Schwartz, A. Etzioni, R. Bayer, H.D. Ochs, J.C Paulson, and J.M. Harlan. 1995. Neutrophil adhesion in leukocyte adhesion deficiency syndrome type 2. J. Clin. Invest. 96:2898-2906.

36. Maly, P., A.D. Thall, B. Petryniak, G.E. Rogers, P.L. Smith, R.M. 
Marks, R.J. Kelly, K.M. Gersten, G.Y. Cheng, T.L. Saunders, et al. 1996. The $\alpha(1,3)$ Fucosyltransferase Fuc-TVII controls leukocyte trafficking through an essential role in L-, E-, and P-selectin ligand biosynthesis. Cell. 86:643-653.

37. Norgard, K.E., K.L. Moore, S. Diaz, N.L. Stults, S. Ushiyama, R.P. McEver, R.D. Cummings, and A. Varki. 1993. Characterization of a specific ligand for P-selectin on myeloid cells. A minor glycoprotein with sialylated O-linked oligosaccharides. J. Biol. Chem. 268:12764-12774.

38. Sako, D., X.-J. Chang, K.M. Barone, G. Vachino, H.M. White, G. Shaw, G.M. Veldman, K.M. Bean, T.J. Ahern, B. Furie, et al. 1993. Expression cloning of a functional glycoprotein ligand for P-selectin. Cell. 75:1179-1186.

39. Weyrich, A.S., X. Ma, D.J. Lefer, K.H. Albertine, and A.M. Lefer. 1993. In vivo neutralization of P-selectin protects feline heart and endothelium in myocardial ischemia and reperfusion injury. J. Clin. Invest. 91:2620-2629.

40. Ridings, P.C., S. Holloway, G.L. Bloomfield, M.L. Phillips, B.J. Fisher, C.R. Blocher, H.J. Sugerman, and A.A. Fowler, III. 1997. Protective role of synthetic sialylated oligosaccharide in sepsis-induced acute lung injury. J. Appl. Physiol. 82:644-651.

41. Bevilacqua, M.P., R.M. Nelson, G. Mannori, and O. Cecconi. 1994. Endothelial-leukocyte adhesion molecules in human disease. Annu. Rev. Med. 45: 361-378

42. Skurk, C., M. Buerke, J.-P. Guo, J. Paulson, and A.M. Lefer. 1994. Sialyl Lewis ${ }^{\mathrm{x}}$-containing oligosaccharide exerts beneficial effects in murine traumatic shock. Am. J. Physiol. (Heart Circ. Physiol.). 267:H2124-H2131.

43. Lefer, A.M. 1995. Role of selectins in myocardial ischemia reperfusion injury. Ann. Thorac. Surg. 60:773-777.

44. Seekamp, A., and P.A. Ward. 1993. Ischemia-reperfusion injury. Agents Actions. 41:137-152.

45. O'Connell, D., A. Koenig, S. Jennings, B. Hicke, H.L. Han, T. Fitzwater, Y.F. Chang, N. Varki, D. Parma, and A. Varki. 1996. Calcium-dependent oligonucleotide antagonists specific for L-selectin. Proc. Natl. Acad. Sci. USA. 93:5883-5887.

46. Hicke, B.J., S.R. Watson, A. Koenig, C.K. Lynott, R.F. Bargatze, Y.F. Chang, S. Ringquist, L. Moon-McDermot, S. Jennings, T. Fitzwater, et al. 1996. DNA aptamers block L-selectin function in vivo. Inhibition of human lymphocyte trafficking in SCID mice. J. Clin. Invest. 98:2688-2692.

47. Yednock, T.A., L.M. Stoolman, and S.D. Rosen. 1987. Phosphomannosyl-derivatized beads detect a receptor involved in lymphocyte homing. J. Cell Biol. 104:713-723.

48. Skinner, M.P., D.J. Fournier, R.K. Andrews, J.J. Gorman, C.N. Chesterman, and M.C. Berndt. 1989. Characterization of human platelet GMP-140 as a heparin-binding protein. Biochem. Biophys. Res. Commun. 164:1373-1379.

49. Aruffo, A., W. Kolanus, G. Walz, P. Fredman, and B. Seed. 1991. CD62/ P-selectin recognition of myeloid and tumor cell sulfatides. Cell. 67:35-44.

50. Handa, K., E.D. Nudelman, M.R. Stroud, T. Shiozawa, and S. Hakomori. 1991. Selectin GMP-140 (CD62; PADGEM) binds to sialosyl-Le ${ }^{\mathrm{a}}$ and sialosyl-Le ${ }^{\mathrm{x}}$, and sulfated glycans modulate this binding. Biochem. Biophys. Res. Commun. 181:1223-1230.

51. Skinner, M.P., C.M. Lucas, G.F. Burns, C.N. Chesterman, and M.C. Berndt. 1991. GMP-140 binding to neutrophils is inhibited by sulfated glycans. J. Biol. Chem. 266:5371-5374.

52. Needham, L.K., and R.L. Schnaar. 1993. The HNK-1 reactive sulfoglucuronyl glycolipids are ligands for L-selectin and P-selectin but not E-selectin. Proc. Natl. Acad. Sci. USA. 90:1359-1363.

53. Nelson, R.M., O. Cecconi, W.G. Roberts, A. Aruffo, R.J. Linhardt, and M.P. Bevilacqua. 1993. Heparin oligosaccharides bind L- and P-selectin and inhibit acute inflammation. Blood. 82:3253-3258.

54. Yuen, C.-T., K. Bezouska, J. O’Brien, M. Stoll, R. Lemoine, A. Lubineau, M. Kiso, A. Hasegawa, N.J. Bockovich, K.C. Nicolaou, and T. Feizi. 1994. Sulfated blood group Lewis ${ }^{\mathrm{a}}$ A superior oligosaccharide ligand for human E-selectin. J. Biol. Chem. 269:1595-1598

55. Mitsuoka, C., N. Kawakami-Kimura, M. Kasugai-Sawada, N. Hiraiwa, K. Toda, H. Ishida, M. Kiso, A. Hasegawa, and R. Kannagi. 1997. Sulfated sialyl Lewis X, the putative L-selectin ligand, detected on endothelial cells of high endothelial venules by a distinct set of anti-sialyl Lewis X antibodies. Biochem. Biophys. Res. Commun. 230:546-551.

56. Yoshino, K., H. Ohmoto, N. Kondo, H. Tsujishita, Y. Hiramatsu, Y. Inoue, and H. Kondo. 1997. Studies on selectin blockers. IV. Structure-function relationships of sulfated sialyl Lewis X hexasaccharide ceramides toward E-, P-, and L-selectin binding. J. Med. Chem. 40:455-462.

57. Norgard-Sumnicht, K.E., N.M. Varki, and A. Varki. 1993. Calcium-dependent heparin-like ligands for L-selectin in nonlymphoid endothelial cells. Science. 261:480-483.

58. Norgard-Sumnicht, K., and A. Varki. 1995. Endothelial heparan sulfate proteoglycans that bind to L-selectin have glucosamine residues with unsubstituted amino groups. J. Biol. Chem. 270:12012-12024.

59. Zakrzewicz, A., M. Gräfe, D. Terbeek, M. Bongrazio, W. AuchSchwelk, B. Walzog, K. Graf, E. Fleck, K. Ley, and P. Gaehtgens. 1997. L-selectin-dependent leukocyte adhesion to microvascular but not to macrovascular endothelial cells of the human coronary system. Blood. 89:3228-3235.

60. Giuffre, L., A.S. Cordey, N. Monai, Y. Tardy, M. Schapira, and O. Spertini. 1997. Monocyte adhesion to activated aortic endothelium: role of L-selectin and heparan sulfate proteoglycans. J. Cell Biol. 136:945-956.
61. Ginsberg, J.S. 1996. Management of venous thromboembolism. N. Engl. J. Med. 335:1816-1828.

62. Hirsh, J. 1996. Comparison of the relative efficacy and safety of lowmolecular-weight heparin and unfractionated heparin for the treatment of venous thrombosis. Semin. Thromb. Hemost. 22(Suppl. 2):7-12.

63. Fareed, J., J.M. Walenga, D. Hoppensteadt, X. Huan, and A. Racanelli. 1988. Comparative study on the in vitro and in vivo activities of seven lowmolecular-weight heparins [published erratum appears in Haemostasis. 1988. 18:following 389]. Haemostasis. 18(Suppl. 3):3-15.

64. Coccheri, S. 1990. Low molecular weight heparins: an introduction. Haemostasis. 20(Suppl. S1):74-80.

65. Lane, D.A., and K. Ryan. 1990. The importance of anti-factor Xa and antithrombin activities of low molecular weight heparins. J. Lab. Clin. Med. 116:269-270.

66. Mammen, E.F. 1990. Fragmin: the new generation antithrombotic agent. Why low molecular weight heparin? Semin. Thromb. Hemostasis. 16(Suppl.):1-4.

67. Sakuragawa, N., and K. Takahashi. 1990. Comparative studies on properties of unfractionated and low molecular weight heparin. Semin. Thromb. Hemostasis. 16(Suppl.):5-11.

68. Freedman, M.D. 1991. Low molecular weight heparins: an emerging new class of glycosaminoglycan antithrombotics. J. Clin. Pharmacol. 31:298-306.

69. Hamano, S., M. Nishiyama, H. Komatsu, H. Miyata, S. Ikeda, and N. Sakuragawa. 1992. Study of anticoagulant mechanism of low molecular weight heparin. Thromb. Res. 65:801-808.

70. Nurmohamed, M.T., H. Ten Cate, and J.W. Ten Cate. 1997. Low molecular weight heparin(oid)s: clinical investigations and practical recommendations. Drugs. 53:736-751.

71. Pineo, G.F., and R.D. Hull. 1997. Low-molecular-weight heparin: prophylaxis and treatment of venous thromboembolism. Annu. Rev. Med. 48:79-91.

72. Lohse, D.L., and R.J. Linhardt. 1992. Purification and characterization of heparin lyases from Flavobacterium heparinum. J. Biol. Chem. 267:2434724355.

73. Pervin, A., C. Gallo, K.A. Jandik, X.-J. Han, and R.J. Linhardt. 1995. Preparation and structural characterization of large heparin-derived oligosaccharides. Glycobiology. 5:83-95.

74. Norgard, K.E., H. Han, L. Powell, M. Kriegler, A. Varki, and N.M Varki. 1993. Enhanced interaction of L-selectin with the high endothelial venule ligand via selectively oxidized sialic acids. Proc. Natl. Acad. Sci. USA. 90:1068-1072.

75. Nelson, R.M., S. Dolich, A. Aruffo, O. Cecconi, and M.P. Bevilacqua. 1993. Higher-affinity oligosaccharide ligands for E-selectin. J. Clin. Invest. 91: 1157-1166.

76. Roux, L., S. Holoyda, G. Sundblad, H.H. Freeze, and A. Varki. 1988. Sulfated N-linked oligosaccharides in mammalian cells. I. Complex-type chains with sialic acids and O-sulfate esters. J. Biol. Chem. 263:8879-8889.

77. Koenig, A., R. Jain, R. Vig, K.E. Norgard-Sumnicht, K.L. Matta, and A. Varki. 1997. Selectin inhibition: synthesis and evaluation of novel sialylated, sulfated and fucosylated oligosaccharides, including the major capping group of GlyCAM-1. Glycobiology. 7:79-93.

78. Conrad, H.E. 1996. Nitrous acid degradation of glycosaminoglycans. In Current Protocols in Molecular Biology. F.M. Ausubel, R. Brent, R.E. Kingston, D.D. Moore, J.G. Seidman, J.A. Smith, K. Struhl, L.M. Albright, D.M. Coen, and A. Varki, editors. John Wiley \& Sons, New York. Unit 17-22A

79. Desai, U.R., H. Wang, and R.J. Linhardt. 1993. Specificity studies on the heparin lyases from Flavobacterium heparinum. Biochemistry. 32:81408145 .

80. Jandik, K.A., K. Gu, and R.J. Linhardt. 1994. Action pattern of polysaccharide lyases on glycosaminoglycans. Glycobiology. 4:289-296.

81. Linhardt, R.J. 1996. Analysis of glycosaminoglycans with polysaccharide lyases. In Current Protocols in Molecular Biology. F.M. Ausubel, R. Brent, R.E. Kingston, D.D. Moore, J.G. Seidman, J.A. Smith, K. Struhl, L.M. Albright, D.M. Coen, and A. Varki, editors. John Wiley \& Sons, New York. Unit 17-13B.

82. Geng, J.-G., K.L. Moore, A.E. Johnson, and R.P. McEver. 1991. Neutrophil recognition requires a $\mathrm{Ca}^{2+}$-induced conformational change in the lectin domain of GMP-140. J. Biol. Chem. 266:22313-22318.

83. Graves, B.J., R.L. Crowther, C. Chandran, J.M. Rumberger, S. Li, K.-S. Huang, D.H. Presky, P.C. Familletti, B.A. Wolitzky, and D.K. Burns. 1994. Insight into E-selectin/ligand interaction from the crystal structure and mutagenesis of the lec/EGF domains. Nature. 367:532-538.

84. Geng, J.G., M.P. Bevilacqua, K.L. Moore, T.M. McIntyre, S.M. Prescott, J.M. Kim, G.A. Bliss, G.A. Zimmerman, and R.P. McEver. 1990. Rapid neutrophil adhesion to activated endothelium mediated by GMP-140. Nature. 343:757-760.

85. Rosen, S.D., and C.R. Bertozzi. 1994. The selectins and their ligands. Curr. Opin. Cell. Biol. 6:663-673.

86. Weis, W.I., K. Drickamer, and W.A. Hendrickson. 1992. Structure of a C-type mannose-binding protein complexed with an oligosaccharide. Nature. 360:127-134.

87. Varki, A., and S. Kornfeld. 1983. The spectrum of anionic oligosaccharides released by endo-beta-N-acetylglucosaminidase $\mathrm{H}$ from glycoproteins. 
Structural studies and interactions with the phosphomannosyl receptor. J. Biol. Chem. 258:2808-2818.

88. Powell, L.D., R.K. Jain, K.L. Matta, S. Sabesan, and A. Varki. 1995 Characterization of sialyloligosaccharide binding by recombinant soluble and native cell-associated CD22. Evidence for a minimal structural recognition motif and the potential importance of multisite binding. J. Biol. Chem. 270:75237532 .

89. Boneu, B. 1996. Glycosaminoglycans: clinical use. Semin. Thromb. Hemostasis. 22:209-212.

90. El Habbal, M.H., L. Smith, M.J. Elliott, and S. Strobel. 1995. Effect of heparin anticoagulation on neutrophil adhesion molecules and release of IL8: C3 is not essential. Cardiovasc. Res. 30:676-681.

91. Leculier, C., O. Benzerara, N. Couprie, A. Francina, Y. Lasne, E. Archimbaud, and D. Fiere. 1992. Specific binding between human neutrophils and heparin. Br. J. Haematol. 81:81-85.

92. Salzman, E.W., R.D. Rosenberg, M.H. Smith, J.N. Lindon, and L. Favreau. 1980. Effect of heparin and heparin fractions on platelet aggregation. J. Clin. Invest. 65:64-73.

93. Horne, M.K., III, and E.S. Chao. 1989. Heparin binding to resting and activated platelets. Blood. 74:238-243.

94. Horne, M.K., III. 1991. Heparin binds normally to platelets digested with Streptomyces griseus protease. Thromb. Res. 61:155-158.

95. Dawes, J. 1993. Interactions of heparins in the vascular environment. Haemostasis. 23(Suppl. 1):212-219.

96. Hemmerich, S., H. Leffler, and S.D. Rosen. 1995. Structure of the $O$-glycans in GlyCAM-1, an endothelial-derived ligand for L-selectin. J. Biol. Chem. 270:12035-12047.

97. Pouyani, T., and B. Seed. 1995. PSGL-1 recognition of P-selectin is controlled by a tyrosine sulfation consensus at the PSGL-1 amino terminus. Cell. 83:333-343.

98. Wilkins, P.P., K.L. Moore, R.P. McEver, and R.D. Cummings. 1995. Tyrosine sulfation of P-selectin glycoprotein ligand-1 is required for high affinity binding to P-selectin. J. Biol. Chem. 270:22677-22680.

99. Wilkins, P.P., R.P. McEver, and R.D. Cummings. 1996. Structures of the $O$-glycans on P-selectin glycoprotein ligand-1 from HL-60 cells. J. Biol. Chem. 271:18732-18742.
100. Lincoff, A.M., J.E. Tcheng, R.M. Califf, T. Bass, J.J. Popma, P.S. Teirstein, N.S. Kleiman, L.J. Hattel, H.V. Anderson, J.J. Ferguson, et al. 1997. Standard versus low-dose weight-adjusted heparin in patients treated with the platelet glycoprotein IIb/IIIa receptor antibody fragment abciximab (c7E3 Fab) during percutaneous coronary revascularization. PROLOG Investigators. Am. J. Cardiol. 79:286-291.

101. Granger, C.B., J. Hirsch, R.M. Califf, J. Col, H.D. White, A. Betriu, L.H. Woodlief, K.L. Lee, E.G. Bovill, R.J. Simes, and E.J. Topol. 1996. Activated partial thromboplastin time and outcome after thrombolytic therapy for acute myocardial infarction: results from the GUSTO-I trial. Circulation. 93: $870-878$.

102. Sobel, B.E. 1997. Heparin and streptokinase. Cardiovasc. Drugs Ther. 11:97-100.

103. Commerford, P.J. 1997. Heparin after acute myocardial infarction. Cardiovasc. Drugs Ther. 11:101-109.

104. White, H.D. 1997. Is heparin of value in the management of acute myocardial infarction? Cardiovasc. Drugs Ther. 11:111-119.

105. Mulligan, M.S., J.B. Lowe, R.D. Larsen, J. Paulson, Z. Zheng, S. DeFrees, K. Maemura, M. Fukuda, and P.A. Ward. 1993. Protective effects of sialylated oligosaccharides in immune complex-induced acute lung injury. J. Exp. Med. 178:623-631.

106. Buerke, M., A.S. Weyrich, Z. Zheng, F.C.A. Gaeta, M.J. Forrest, and A.M. Lefer. 1994. Sialyl Lewis ${ }^{\mathrm{x}}$-containing oligosaccharide attenuates myocardial reperfusion injury in cats. J. Clin. Invest. 93:1140-1148.

107. Lefer, D.J., D.M. Flynn, M.L. Phillips, M. Ratcliffe, and A.J. Buda. 1994. A novel sialyl Lewis ${ }^{\mathrm{x}}$ analog attenuates neutrophil accumulation and myocardial necrosis after ischemia and reperfusion. Circulation. 90:2390-2401.

108. Flynn, D.M., A.J. Buda, P.R. Jeffords, and D.J. Lefer. 1996. Sialyl Lewis ${ }^{\mathrm{x}}$-containing carbohydrate reduces infarct size: role of selectins in myocardial reperfusion injury. Am. J. Physiol. (Heart Circ. Physiol.). 271:H2086H2096.

109. Tojo, S.J., S. Yokota, H. Koike, J. Schultz, Y. Hamazume, E. Misugi, K. Yamada, M. Hayashi, J.C. Paulson, and S. Morooka. 1996. Reduction of rat myocardial ischemia and reperfusion injury by sialyl Lewis $\mathrm{x}$ oligosaccharide and anti-rat P-selectin antibodies. Glycobiology. 6:463-469. 